\title{
Source separation, transportation, pretreatment, and valorization of municipal solid waste: a critical review
}

\author{
Xuemeng Zhang ${ }^{1} \cdot$ Chao Liu $^{1} \cdot$ Yuexi Chen ${ }^{1} \cdot$ Guanghong Zheng ${ }^{1} \cdot$ Yinguang Chen $^{1}$
}

Received: 4 May 2021 / Accepted: 25 October 2021 / Published online: 10 November 2021

(c) The Author(s), under exclusive licence to Springer Nature B.V. 2021

\begin{abstract}
Waste sorting is an effective means of enhancing resource or energy recovery from municipal solid waste (MSW). Waste sorting management system is not limited to source separation, but also involves at least three stages, i.e., collection and transportation (C\&T), pretreatment, and resource utilization. This review focuses on the whole process of MSW management strategy based on the waste sorting perspective. Firstly, as the sources of MSW play an essential role in the means of subsequent valorization, the factors affecting the generation of MSW and its prediction methods are introduced. Secondly, a detailed comparison of approaches to source separation across countries is presented. Constructing a top-down management system and incentivizing or constraining residents' sorting behavior from the bottom up is believed to be a practical approach to promote source separation. Then, the current state of C\&T techniques and its network optimization are reviewed, facilitated by artificial intelligence (AI) and the Internet of Things technologies. Furthermore, the advances in pretreatment strategies for enhanced sorting and resource recovery are introduced briefly. Finally, appropriate methods to valorize different MSW are proposed. It is worth noting that new technologies, such as AI, show high application potential in waste management. The sharing of (intermediate) products or energy of varying processing units will inject vitality into the waste management network and achieve sustainable development.
\end{abstract}

Guanghong Zheng

zhenggh@ tongji.edu.cn

Yinguang Chen

yinguangchen@tongji.edu.cn

1 State Key Laboratory of Pollution Control and Resource Reuse, School of Environmental Science and Engineering, Tongji University, 1239 Siping Road, Shanghai 200092, People's Republic of China 


\section{Graphical abstract}

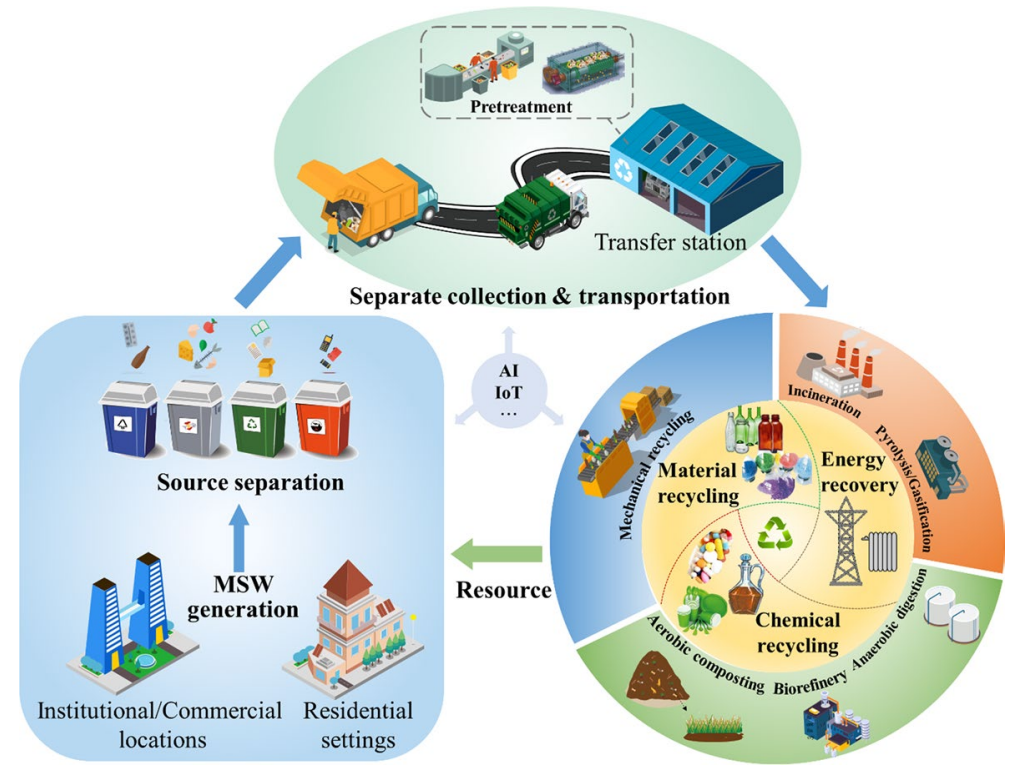

Keywords Municipal solid waste (MSW) · Waste sorting $\cdot$ Route optimization · Resource recovery $\cdot$ Waste management

\section{Introduction}

Along with the rapid industrialization and population explosion, the increasing amount of municipal solid waste (MSW) has gradually become one of the significant bottlenecks restricting the sustainable development of economy, environment, and society (Heidari et al., 2019). It is reported that the global annual production of MSW currently constitutes over 2 billion tonnes (Shah et al., 2021), and is expected to be doubled to about 4 billion tonnes by 2100 (Ebrahimian \& Karimi, 2020). In the absence of appropriate and timely waste management, tons of MSW lead to serious public health issues, environmental degradation, and natural resource depletion (Mohammadi et al., 2019). The emerging circular economy provides a zero-waste management model through integrated waste recycling and technological digitization (Kurniawan et al., 2021). It can not only eliminate the adverse environmental and social impacts of MSW's indiscreet or organized discards, but also bring economic benefits to drive the sustainable development of the whole MSW management (MSWM) (Thomas \& Soren, 2020). Moreover, following the new financial situation after coronavirus disease 2019 (COVID-19) pandemic, the "industrial chain" of waste sorting and valorization may become one driving force for promoting world economic growth.

The Environmental Protection Agency's definition of MSW is mostly waste produced in households, residential settings, commercial and institutional locations, not including industrial, hazardous, or construction and demolition waste (Agency, 2016). Specifically, MSW constituents consist of food waste (FW) (25-70\%), garden waste, yard 
trimmings, paper, glass, metals, plastics, rubbers, textiles, electronics, etc. (Ashani et al., 2020), excluding waste from sewage networks and treatment (such as sewage sludge) (Malinauskaite et al., 2017). There are considerable differences in the generation and composition of MSW in various regions, influenced by local natural resources, culture, and socioeconomic development (Vazquez et al., 2020). For example, the MSW production rate is approximately 170 million tons per year in China (Zhou et al., 2014), of which $55 \%$ is biodegradable waste, compared to only $15.1 \%$ in the USA (Mukherjee et al., 2020). It leads to a possibility that China might pay more attention to the treatment of biodegradable waste. Different types of waste materials necessitate various treatment methods. Therefore, each country and region should carefully assess and supplement its own MSW generation and physical composition database to establish a realistic national MSWM strategy.

Effective waste sorting and separation is the basic strategy for MSWM and the most effective way to increase the recovery rate of MSW (such as the EU's requirement of 65\% recovery by 2030) (Calabro \& Satira, 2020). Shanghai and Beijing in China also successively issued relevant laws and regulations on source separation to solve the heterogeneity problem in the resource utilization of MSW. At the same time, the development of system technologies such as Internet + and artificial intelligence (AI) has promoted the residents' awareness of source separation. MSW enters the material flow management system through collection and transportation (C\&T), and researchers preferred to model and a variety of algorithms to solve the contradictory problems of transportation cost, greenhouse gas (GHG) emission, and social concern in this process (Ferronato et al., 2020). Moreover, the application of cross-disciplinary tools, such as geographic information system (GIS) and Internet of Things (IoT), provided a more refined management approach for C\&T systems (Abdullah et al., 2018; Cetin, 2015b). The purpose of source separation and intermediate treatment station is to select the most suitable value-added treatment method or to improve the potential of resource utilization (Calabro \& Satira, 2020), rather than to adopt landfills with low resource potential and more emerging pollutants, such as antibiotic resistance genes (Li et al., 2020a), pharmaceutical and personal care products ( $\mathrm{Yu}$ et al., 2020), and microplastics (Golwala et al., 2021).

The concept of valorizing MSW, transforming it into energy, or producing various products is an attractive alternative to landfills, which shows the potential of carbon mitigation and revenue generation (Kannah et al., 2020; Ooi et al., 2021). There were plenty of valorization methods of MSW, including mechanical recycling, thermal process, and biological strategy, but the substrate boundary between them was not noticeable. For example, plastic waste and organic fraction of municipal solid waste (OFMSW) can be recycled by thermal conversion (e.g., incineration and pyrolysis) (Hasan et al., 2021), yet it is apparent that plastic recovery is much sustainable. Furthermore, the concept of 'combination' has proved to be promising and effective in biological strategies, such as co-digestion of OFMSW and wastewater sludge (Amodeo et al., 2021), integration of anaerobic digestion and gasification technology (Zhang et al., 2020a), synergistic pyrolysis of MSW (Lee et al., 2020), the combination of pretreatment technology (Bala \& Mondal, 2020; Kannah et al., 2020). Substrate combination or technology integration was designed to produce the target products with high yield and achieve resource utilization by MSW from different sources. The valorizing products of MSW and its economic value could not only be supplied to the MSWM system, but some recycled materials could also be used in sustainable urban landscaping and soil protection (Cetin, 2013, 2015a). Nevertheless, landfills still dominate MSW treatment, with $52.1 \%$ of MSW in the USA still used for landfill treatment in 2017. Simultaneously, the MSW resource utilization methods have not been unified in 
commercial applications, and the whole MSWM could not fully realize the positive output of energy and economy, which strongly depends on the economic development locally.

Although there were some review papers on valorization methods of MSW, they preferred the resource utilization methods of a particular MSW, such as anaerobic fermentation (Chen et al., 2021), slow pyrolysis (Hasan et al., 2021; Lee et al., 2020), preparation of high-value chemicals (Ebikade et al., 2020; Kumar et al., 2021), and production of biofuels (Kannah et al., 2020), and even the disposal of hazardous waste related to COVID19 (Klemeš et al., 2020). However, under the background of the continuous deepening of waste sorting, the whole process from the generation, source separation, collection and transportation, pretreatment, and resource utilization of MSW has not been systematically and comprehensively reviewed. Thus, this paper aims to: (1) summarize the generation, physical composition of MSW and the reasons for their differences; (2) compare the status and promotion factors of waste source separation in various countries; (3) list the latest technological progress of MSW collection, transportation, automatic sorting and pretreatment; and (4) figure out suitable resource utilization method for various types of MSW in the future.

\section{MSW generation and source separation}

\subsection{Generation and composition of MSW}

MSW is a heterogeneous solid waste stream generated by human activities inevitably (Yan et al., 2020), which has non-point source pollution characteristics in contrast with industrial solid waste, hazardous waste (including medical waste), and construction waste. Numerous studies investigated the generation and characteristics of MSW in various countries and regions intensively, including waste quantity, waste composition, moisture content, and calorific value (Abylkhani et al., 2019; Mmereki et al., 2016). The generation and composition of MSW are markedly geographically variable (Shi et al., 2021), whose forecast is an initial step in planning and establishing a waste sorting management system (Abbasi \& El Hanandeh, 2016; Gu et al., 2015). It determines its subsequent treatment methods and potential for resource recovery.

\subsubsection{Generation of MSW}

According to data from the World Bank in 2018 (Kaza et al., 2018), the average MSW generated rate was $0.74 \mathrm{~kg}(\mathrm{~kg})$ per capita per day (PCPD) globally; however, national generation rates of MSW fluctuated widely from 0.11 to $4.54 \mathrm{~kg}$ PCPD. The total MSW generation grows primarily based on the gross domestic product (GDP) (Lu et al., 2017), and population size (Oribe-Garcia et al., 2015). Generally, the higher GDP growth rate would significantly increase the per-capita and total waste generation rate. Similarly, there was a significant correlation between population growth and MSW generation in high-income countries, but the effect was insignificant in low-income countries (Zambrano-Monserrate et al., 2021). Besides, the strict demographic policy would boost the per-capita waste generation rate but have little impact on the total MSW generation (Xiao et al., 2020b). For instance, East Asia and Pacific region generated the most in absolute terms, an estimated 468 million tonnes in 2016, accounting for 23\% of global MSW production; yet the percapita generation rates of MSW were only $0.56 \mathrm{~kg}$ PCPD there, which was only $25 \%$ of 
the USA (2.24 kg PCPD) and 15\% of Singapore (3.72 kg PCPD). Therefore, there is not a manifest correlation between per-capita waste generation rate and total MSW generation due to the uneven distribution of the population.

The generation rates of MSW generally have spatial dependence, depending on but not limited to factors such as income levels, urbanization rate, road conditions, energy consumption (Gui et al., 2019; Liu \& Wu, 2011). The World Bank used a regression model to estimate the expected growth of the generation rate of MSW in each country, taking GDP per capita in each country as an independent variable. Homoplastically, Lebreton and Andrady calculated MSW generation per capita through GDP per capita (USA dollar) by introducing an empirical function (Eq. 1.), where $a=11.434$ (lower bound: 11.218, upper bound: 11.953) and $b=0.3433$ (lower bound: 0.3565, upper bound: 0.3298) (Lebreton \& Andrady, 2019). Gui et al. explored the spatial dependence of MSW by designing two spatial panel models and using panel data of 285 cities in China from 2006 to 2015. This study revealed a mutual improvement relationship between MSW generation and GDP per capita, rather than an inverted U-shape as predicted by the environmental Kuznets curve (Gui et al., 2019), which fell after an inflection point. Liu et al. studied the factors influencing the generation of MSW in China through a specifically principal component analysis and cluster analysis. The proportion of the population played the most significant role in all factors; however, the relationship between China's GDP growth and the MSW generation is not as clear-cut as the generally assumed developed countries (Liu \& Wu, 2011). Ma et al. also pointed out that MSW generation might not increase with GDP growth in developing countries, and it was important to consider the influences of other factors (ZambranoMonserrate et al., 2021).

$$
\text { MSW generation per capita }=\mathrm{a}(\text { GDP per capita })^{\mathrm{b}}
$$

Apart from the conventional socioeconomic factors above, more and more studies focused on the impact of emerging factors (e.g., electronic commerce, season, housing type, education level, household size, etc.) on MSW generation (Adelodun et al., 2021; Getahun et al., 2012; Tian et al., 2016; Xiao \& Zhou, 2020). For example, the rise of electronic commerce has boosted the prosperity of the express delivery industry. In densely populated central and eastern China (Tian et al., 2016), couriers' recycling behavior may alleviate the growing problem of MSW. When other variables remain unchanged and the Internet penetration rate in western China increases by $1 \%$, per-capita MSW generation would remarkably decrease by $1.738 \mathrm{~kg}$ due to the improvement in environmental awareness (Guo et al., 2017; Xiao \& Zhou, 2020). Given various variables mentioned above, advanced AI prediction systems have shown advantages over traditional models such as regression analysis, material flow analysis, and time series analysis models in waste management research, especially modeling complex nonlinear behavior. To predict the monthly MSW production in the Logan City Council area in Queensland, Australia, Abbasi et al. took and compared four intelligent system algorithms, including support vector machine, adaptive neuro-fuzzy inference system, artificial neural network (ANN), and k-nearest neighbors. This study showed that the AI model could successfully establish MSW prediction models (Abbasi \& El Hanandeh, 2016). ANN is the most widely used to develop predictive MSW generation models due to its robustness, fault tolerance, and applicability in describing the complicated relationship between variables in a multivariate system (Abdallah et al., 2020). However, ANN cannot judge the correlation between various variables, whose data also need to be preprocessed (Abdallah et al., 2020). Moreover, Vu et al. proposed that weekly climate and socioeconomic factors would also have time-lagged 
effects on the ANN waste prediction model (Vu et al., 2019a; Vu et al., 2019b). Since the establishment and calibration of AI systems require a large amount of MSW's data to drive, insufficient practical data will become the biggest challenge for AI systems in depth utilization.

\subsubsection{Physical composition of MSW}

The physical composition of MSW refers to categorizing types of materials in MSW. Investigating the MSW composition has a crucial reference role in estimating the recovery potential and GHG emissions and formulating subsequent waste sorting, transportation, and treatment strategies in this area. The physical compositions of MSW in different regions are shown in Table S1. Various studies have not been consistent statistics on the composition of MSW (Gu et al., 2017). The World Bank characterized the global MSW stream to contain food and green waste (i.e., organic) as the most significant percentage (44\%), followed by paper and cardboard (17\%), plastics (12\%), glass $(5 \%)$, metals $(4 \%)$, rubber and leather $(2 \%)$, wood $(2 \%)$, and others (14\%) (Kaza et al., 2018). As shown in Fig. 1, the compositions of MSW in developing countries and developed countries were dissimilar through the ternary chart compared, i.e., OFMSW, especially FW, was dominant. Generally, the composition of MSW varies considerably by GDP. Compared with MSW from developing countries, the amount of paper, plastic, metal, and glass in developed countries is higher, while FW is lower (Benis et al., 2019; Zhou et al., 2014). The percentage of organic matter in MSW might be negatively correlated with income level. For example, FW in Singapore only accounted for $12.6 \%$ of MSW, while it was as high as $77 \%$ in Niger Delta Region. However, even in the more developed Chinese cities, such as Beijing (Wang \& Wang, 2013) and Shanghai (Nie et al., 2018), FW was still 20\% higher than those in most European and American countries (Table S1.). It might be because Chinese people prefer unpackaged and less packaged food raw materials (Chen et al., 2010b;

Fig. 1 Comparison of MSW compositions in developed countries and developing countries. KOR, Oman, USA, CHN, and IND are abbreviations for the Republic of Korea, the Sultanate of Oman, the United States of America, China, and India

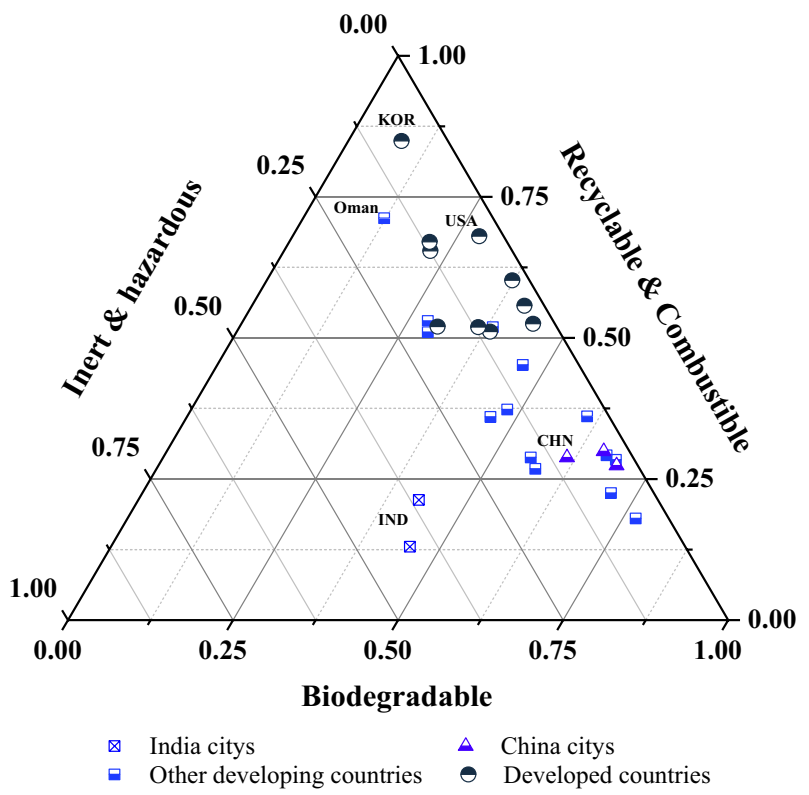


Gu et al., 2017). Therefore, the MSW generation and physical composition might have significantly been decoupled from the local income level (Zhu et al., 2020). Besides, the abundance of natural resources and climatic conditions also significantly affected the characteristics of MSW (Gu et al., 2015), yet they rarely analyzed their impact separately.

\subsection{Importance and impact factors of source separation}

As a starting point for material flow management, source separation of MSW mentioned refers to the waste sorting at the generated place before transportation, whose purpose is to reduce waste generation better, recovery of available resources, and hazardous waste disposal (Tai et al., 2011; Zhang et al., 2019). Unlike the sorting and separation during the pretreatment mentioned later, source separation starts from the generation of MSW, affecting the whole waste management process. A practical source separation strategy is a prerequisite for reducing intermediate processing facilities and increasing the recovery rate (Calabro \& Satira, 2020). Chen et al. presented a community investigation demonstrating that source separation could not only reduce the load of landfills, the moisture of waste incineration, and increase the lower heating value of MSW, but also reduce the carbon emission by at least $66.8 \%$ (Chen et al., 2020). The source separation program would significantly reduce the relative per-capita waste generation through the spatial-two-stageleast squares models analysis (Zhao et al., 2020). However, many challenges remain, such as people's attitudes, treatment facilities, economic benefits.

\subsubsection{Comparison of source separation}

According to physical waste composition and economic conditions in various regions, there are different requirements for source separation. Developed countries began to carry out source separation education 30 years ago and have sufficient infrastructure to collect them separately (Dehkordi et al., 2020). Table 1 shows the comparison of source separation of MSW in some regions. For example, as an environmental leader in the Asia area, more than $92 \%$ of municipalities have source-separated collection programs in Japan (Matsumoto, 2011). Only $1 \%$ of MSW was a sanitary landfill after source separation. However, it took Japanese residents considerable time and effort to sort recyclable waste at home (Takahashi, 2020). In comparison, Sweden, where advocates economic rationalism, fully considers economic incentives and source-separated FW collection. It promoted the systematic improvement in roadside collection systems and drastically enhanced the recovery rates (Takahashi, 2020). Furthermore, Andersson et al. argued that a separated FW collection system in Sweden was generally more effective than a weight-based MSW tariff, reducing the amount of MSW incinerated and increasing recovery of materials and biomass energy (Andersson \& Stage, 2018). Therefore, source separation should sufficiently consider the bioavailability and economic cost of FW. Hong Kong introduced an optical bag system to encourage residents to put FW into green optical bags and other waste into shared plastic bags (Woon \& Lo, 2016). In addition, Bulgaria was also a successful case of source classification. The collection system of Bulgaria included three containers: green (glass), yellow (metal and plastic), and blue (paper and cardboard) (Stoeva \& Alriksson, 2017). Nonetheless, residents were not keen on waste separation in small uneducated Bulgarian villages with low incomes (Vasileva \& Ivanova, 2014).

Developing countries have also been exploring suitable source separation methods, but the implementation rate is not high. As stated above, organic waste in developing countries 


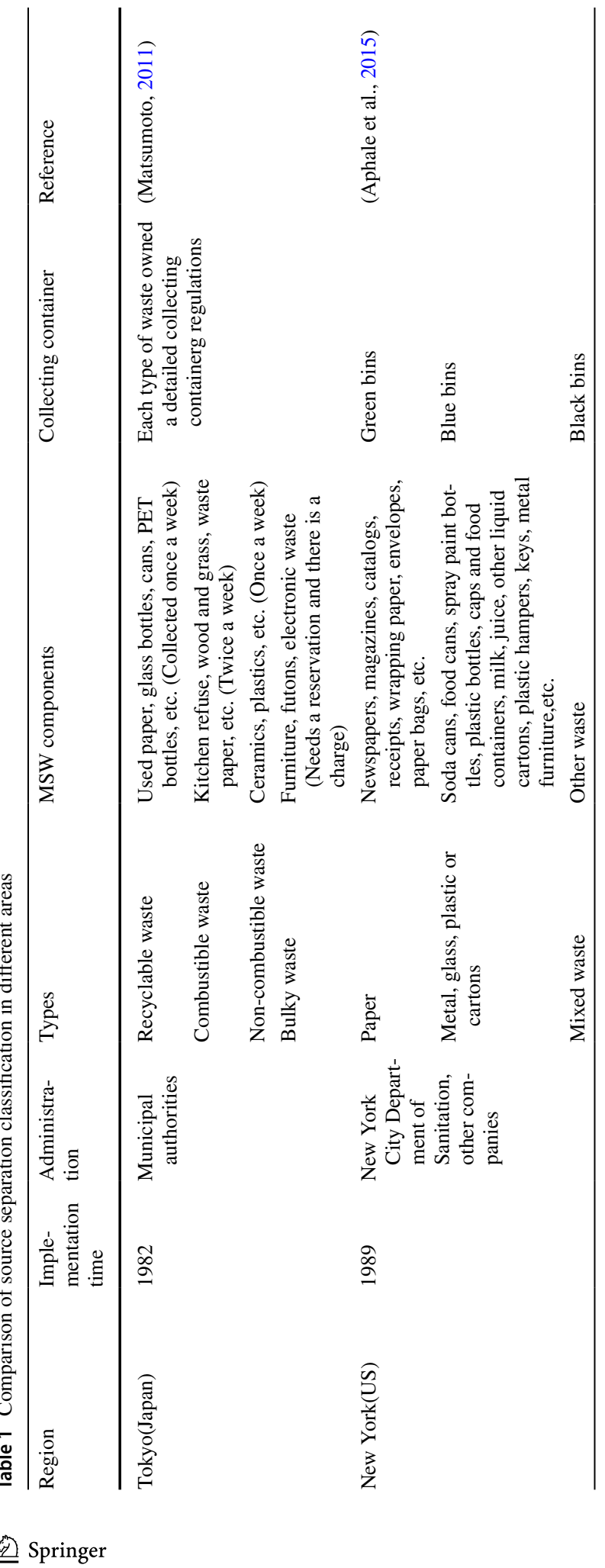




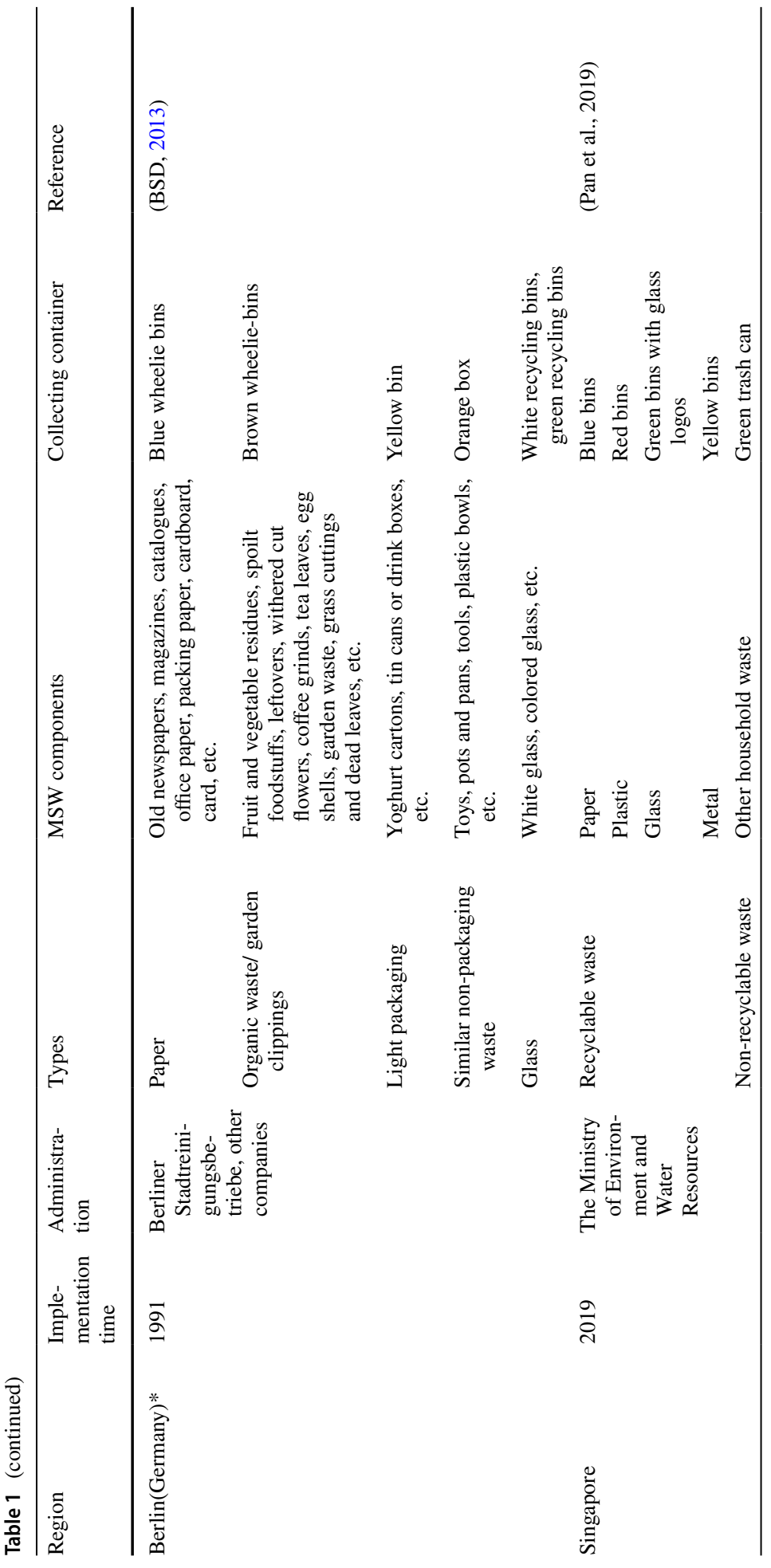




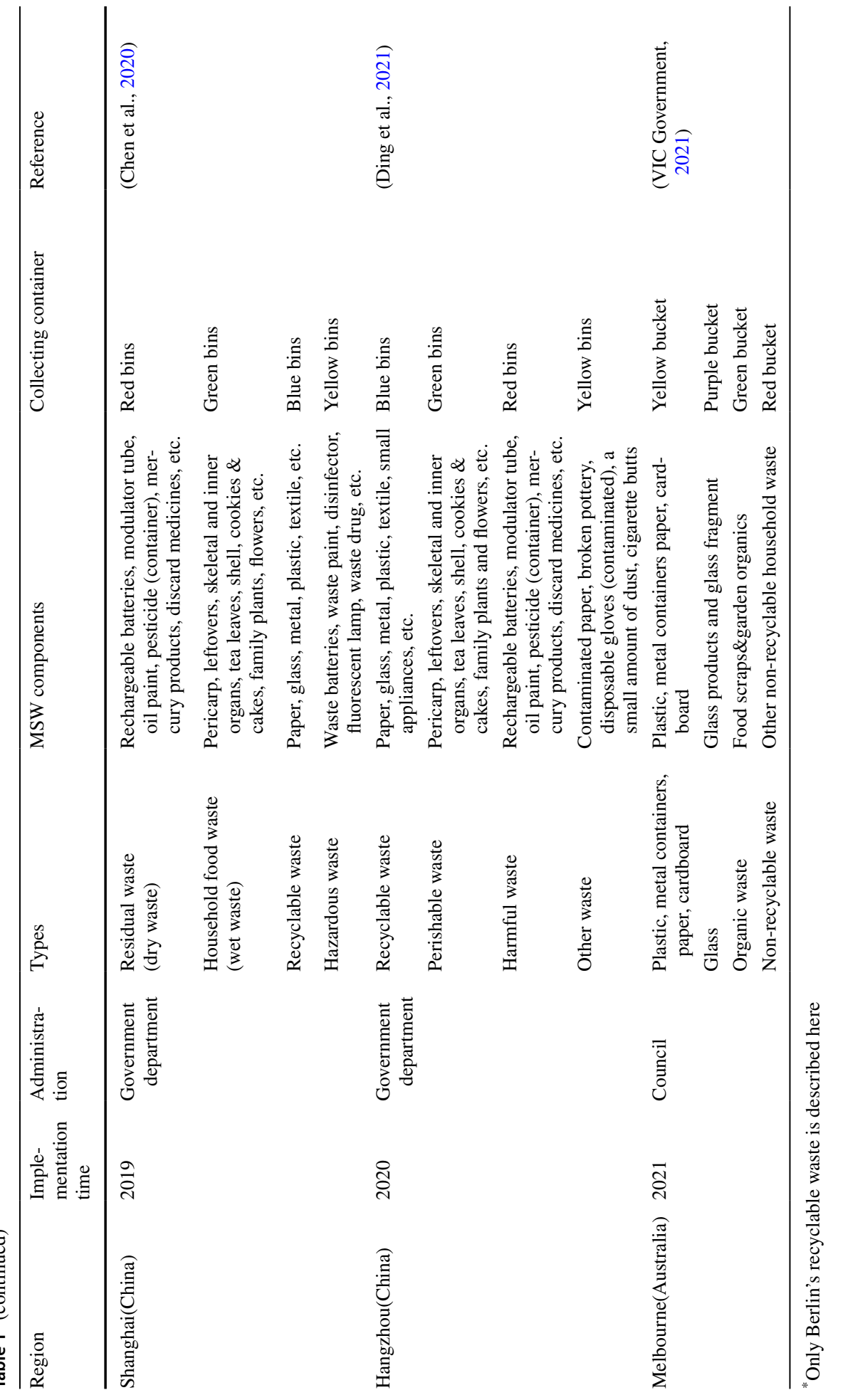


was high in content and rich in moisture. If there was a lack of overall management and treatment facilities between various departments, sorted waste was again artificially mixed during the transfer process, although source separation was carried out. It would lose the significance of source separation, increase the cost burden, and exert an unpredictable negative impact on the citizens' willingness (Xiao et al., 2020a). Ghana encouraged source separation through economic incentives (Owusu et al., 2013). Malaysia strictly implements compulsory source separation through Act No. 672 (Fauziah \& Agamuthu, 2012), yet most Malaysians do not know that compulsory source separation is necessary for recycling (Moh, 2017). In July 2019, Shanghai took the lead in the first implementation of a new waste management policy in China, the "Regulations of Shanghai Municipality on the administration of municipal solid waste," which divides MSW into residual waste (dry waste), household food waste (wet waste), hazardous waste, and recyclable waste (Table 1.) (Chen et al., 2020; Tong et al., 2020). By June 2020, the sorting rate of household food waste had increased to $99.5 \%$ in Shanghai, basically forming a whole-process source separation, collection, and transportation system (Wang et al., 2021b). Besides, rural areas in Hangzhou, China, proposed the ' $2+\mathrm{T}$ ' model (biodegradable waste, other waste, and toxic waste), which effectively separated the biodegradable waste for subsequent reduction and resource treatment (Li et al., 2019). However, source separation is not as fine as possible, and social acceptability must be considered in economic and environmental factors to formulate the most locally appropriate waste sorting policy (Nie et al., 2018). The factors affecting source separation of MSW are introduced in detail below.

\subsubsection{Factors contributing to source separation}

Sustainable source separation management requires the continuous participation of the government, municipal sector (private sector), and the public. Multiple studies examined the internal factors that affect people's waste sorting behavior, such as habitual attitude (Moh, 2017), satisfaction (Wang et al., 2020), moral norm (Razali et al., 2020), environmental awareness (Echegaray \& Hansstein, 2017; Zhang et al., 2017; Fan et al., 2019), family time (family structure)(Matsumoto, 2011), peer-pressure (Lu \& Sidortsov, 2019), public education (Miafodzyeva \& Brandt, 2013; Vasileva \& Ivanova, 2014), and gender ratio. Economies of scale and cost drivers vary by waste types (Greco et al., 2015). Relevant departments and organizations usually adopt the traditional top-down approach when implementing recycling programs, tending to use only economic and political means to try to make the family part of sustainable development, such as a combination of education and punishment. Zhang et al. developed a "Green House" program that collects and categorizes the mixed waste manually on a conveyor belt into dry and wet waste (Zhang et al., 2016). Although it can reduce the amount of waste by $37 \%$, there was a lack of government support and public participation, with 1,982 RMB lost per month, making it challenging to operate sustainably. The ordered probability regression studied the MSW source separation activities of residents in Suzhou and five community groups (Zhang \& Wen, 2014). It was believed that the main determinants of residents' source separation behavior were age, facilities, and preferential government policies. Nevertheless, only the intercept survey failed to show the influence of factor changes (such as time changes) on sorting behavior. The top-down approach to governance has produced passive citizens who may be more supportive of flexible classification policies (Hou et al., 2020; Moh, 2017). In the initial stage of waste sorting, the down-up co-production approach through the governmentvolunteer consortium's synergy and the peer-pressure effect was an effective method (Lu 
\& Sidortsov, 2019). Wang et al. established the concept of IoT-enabled accountability in MSW source separation based on the perspective of accounting theory and demonstrated its validity through several case studies (Wang et al., 2021a). However, it was noted that factors, such as fines, charges, time, procedures, and rules, under the compulsory policy breed negative attitudes toward source separation (Wu et al., 2021). In addition, external factors such as the types of recycled materials, classification policies (Hou et al., 2020), recycling plans (Stoeva \& Alriksson, 2017), market facilitators, and government factors (Xu et al., 2017), economic incentives, or penalties (Varotto \& Spagnolli, 2017) also affected residents' recycling behavior. Knickmeyer et al. had detailed the social factors affecting source separation (Knickmeyer, 2020).

The research mentioned above only focuses on user behavior and does not consider the development system's technical aspects. A sustainable waste management plan should build an overall treatment system from top to bottom and promote waste sorting behavior from bottom to top. Adopting policies to improve disposal capacity is one of the ways to achieve stable recyclable waste management (Ko et al., 2020). Management, facilities, and services require the continuous participation of the government and municipal departments or private companies. For example, FW treatment plants should be built as soon as possible to prevent traditional treatment methods to treat classified FW in areas where wet and dry classification was carried out (Xiao et al., 2020b). Establishing waste management associations between neighboring cities can reduce waste management service costs by $26 \%$ (Chifari et al., 2017). It is necessary for developing countries that started garbage sorting late to monitor waste sorting for a long time ( $\mathrm{Li}$ et al., 2019). Some communities have launched smart dustbins, which delivered kitchen waste or recyclables to different bins by scanning the code and returning the corresponding points or money (the Green Account). Li et al. developed a method for identifying kitchen waste and dry waste based on volume density, which can test the accuracy of waste classification, but did not modify solid waste in different regions ( $\mathrm{Li}$ et al., 2020b). The Internet + method would be a unique and effective way to recycle recyclable waste in developing countries (Xiao et al., 2018). In the future, Internet technology should be used to establish a comprehensive information platform, apply technologies such as the Internet of Vehicles, IoT, and Big Data, develop intelligent classification equipment, and comprehensively consider environmental, economic, and social factors to achieve sustainability source classification strategy.

\section{Collection and transportation of MSW}

\subsection{Overview of collection and transportation techniques}

Collection and transportation (C\&T) techniques remove MSW from its source and transport it to transfer stations (TS), processing facilities, or disposal sites (Rodrigues et al., 2016; Yadav \& Karmakar, 2020). Only a few researchers paid attention to C\&T cost and environmental effect, but most focused on the final treatment. Actually, because of high labor intensity and extensive use of transportation tools, 50-75\% of total MSWM expenditures were spent on C\&T in developed countries, while this proportion even reached 70-90\% in developing countries such as India (85\%) (Amal \& Chabchoub, 2018; Nasiri et al., 2017; Nguyen-Trong et al., 2017; Yadav \& Karmakar, 2020). As shown in Table 2, five common methods of waste collection were reviewed. Clearly, the collection methods of MSW varied remarkably among different regions due to the imbalance in economic 


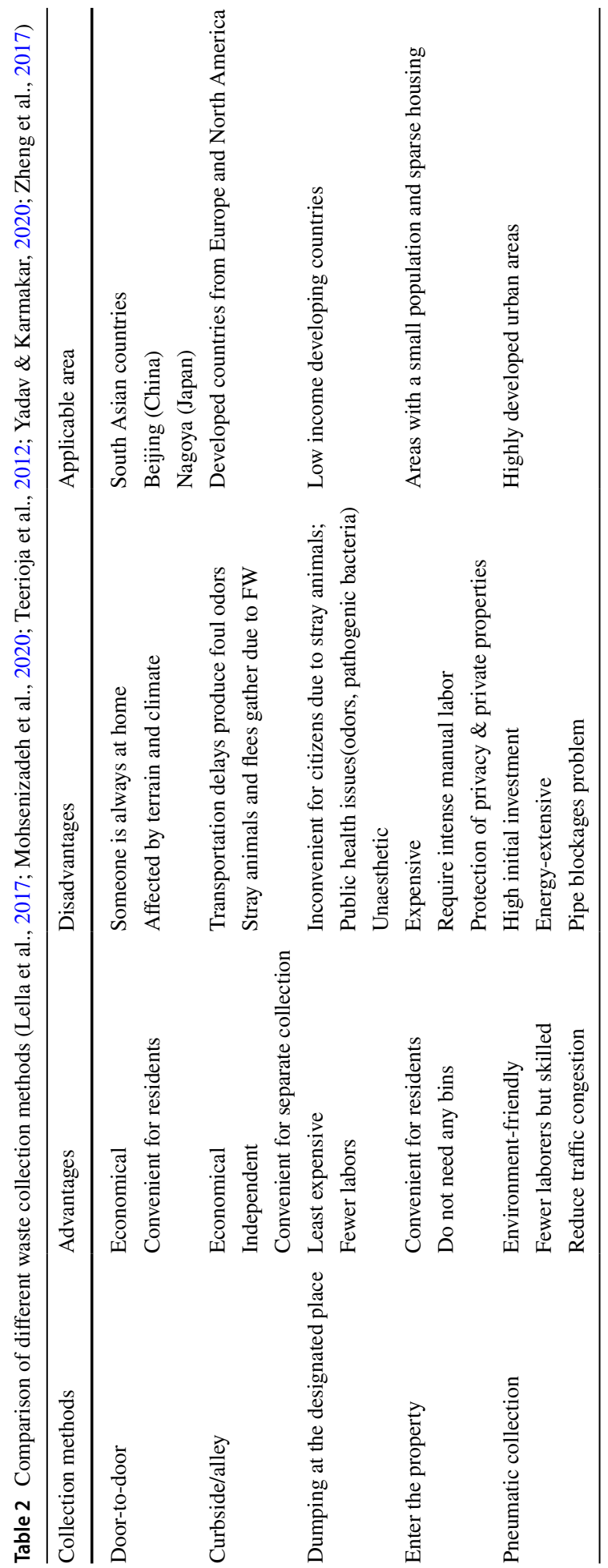


development. Generally, collection methods adopt isolated MSW mechanical collection systems in America and Europe's developed countries, such as entering the property and pneumatic collection (Lella et al., 2017; Mohsenizadeh et al., 2020; Teerioja et al., 2012). However, common practices in developing countries are informal recycling, scavengers, or unorganized dumping, whose collection requires many manual labors (Papageorgiou et al., 2009; Yadav \& Karmakar, 2020). The environmental effects of C\&T techniques mainly originated from unorganized GHG emissions and odor gases in transportation (Boies et al., 2009; Sánchez-Arias et al., 2019; Zhou et al., 2017). Subsequently, fossil energy depletion, environmental pollution, human health, economic costs, and the aesthetics of C\&T facilities, in turn, caused public social concern, that is, citizens' subjective choices (Chester et al., 2008). Therefore, the objectives of optimizing C\&T techniques are mostly around one or several factors of economic cost, environmental and social impact, which are also the goal of sustainable development (Bulatov et al., 2021; Yousefloo \& Babazadeh, 2020).

Vehicles are the primary C\&T instrument, whose main job is to load, compress, transport the MSW, and unload it into TS or the final disposal/processing facility (Mohsenizadeh et al., 2020). Figure S1 illustrates the common C\&T system, i.e., single-stream (mixed collection) and multiple streams (separate collection). After generation of MSW, it relies on manual operation for source separation or manpower transportation tools (such as hand rickshaws and tricycles) to transport to the community transfer point, and then transport to the nearest TS through primary collection vehicles (PCVs) such as tractor-trailers, mini trucks. As in Beijing and Shanghai, communities were required to use special collection tools to avoid "separating from the source but mixing in the middle"(Tai et al., 2011). Finally, the secondary collection vehicles (SCVs), mainly heavyweight carrying vehicles, transfer the pre-treated MSW to the final disposal/processing facility (Yadav et al., 2020). Specifically, TS is an intermediate station between the processing /disposal facility and MSW generation source, which is also a docking station for PCVs and SCVs. MSW through the PCVs transported is compressed by various technologies in the TS and then loaded onto the SCVs (Fig. S1). A study based on life cycle assessment (LCA) showed that the construction of a TS could reduce the impact of global warming potential by $44.9 \%$ and cumulative energy demand rates by $51.7 \%$ compared to directly transferring to a sanitary landfill (Taşkin \& Demir, 2020). Therefore, TS could increase the efficiency of wide-area collection and transport. Besides, TS adopting dump floors and surge tank technology was more economical and environmental-friendly than the direct dump in the transportation field.

Selecting an economically, socially, and environmentally C\&T system is a significant challenge. Recent studies have been primarily based on the optimization of the existing MSW C\&T network design, which is a tactical or operational level decision (Ghiani et al., 2014), including (1) optimization of vehicle routes; (2) modeling of facility location; (3) flow allocation (Yadav \& Karmakar, 2020; Yadav et al., 2020). Other factors were also reported. Goes et al. presented that eco-driving technology not only could impact fuel economy, provide economic returns based on mileage, but also mitigate GHG and air pollutants emissions (Goes et al., 2020). Furthermore, Mohsenizadeh et al. presented Ankara's case study demonstrating that transport vehicles' speed variations would not cause significant changes in $\mathrm{CO}_{2}$ emissions and economic costs (Mohsenizadeh et al., 2020). 


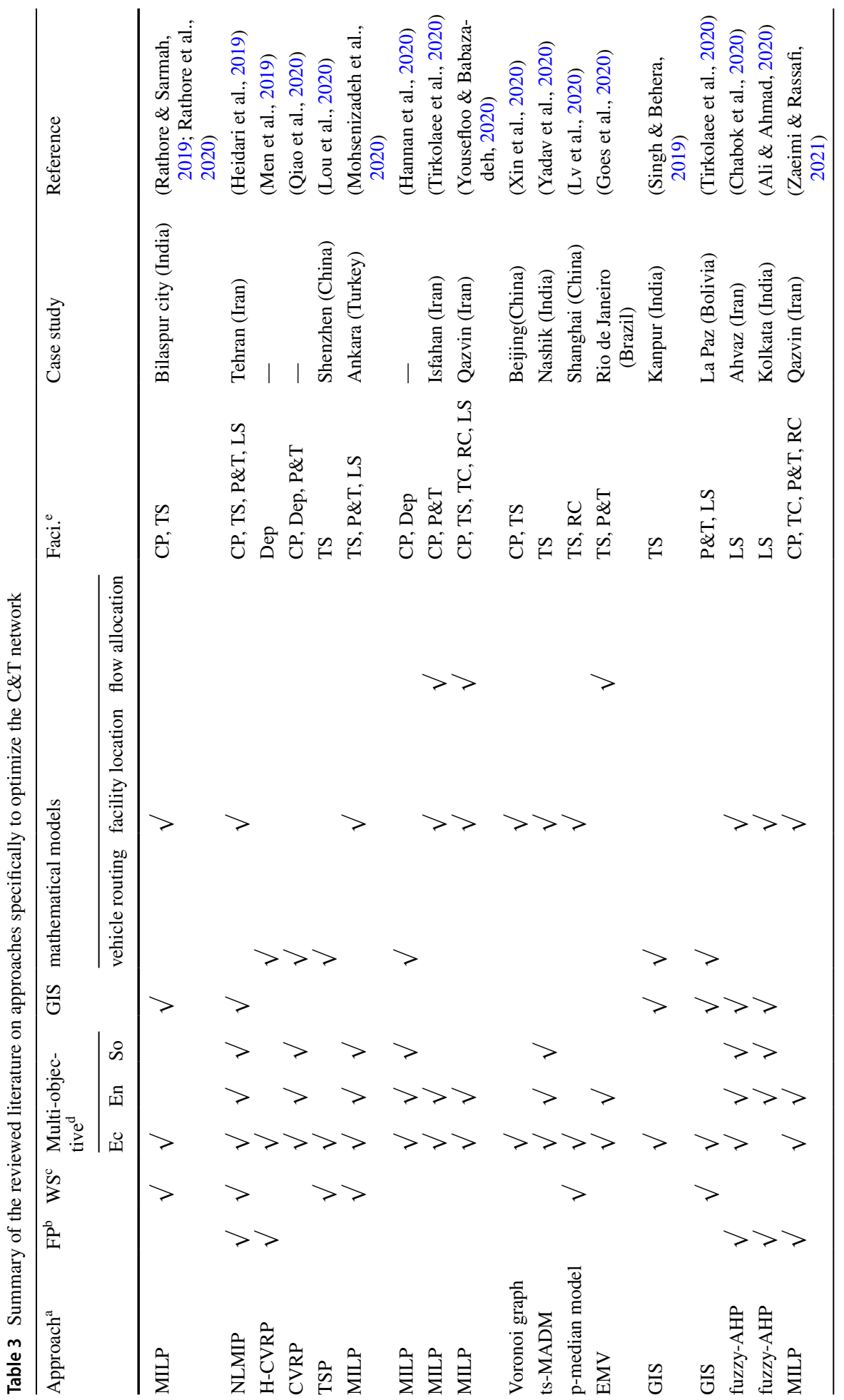




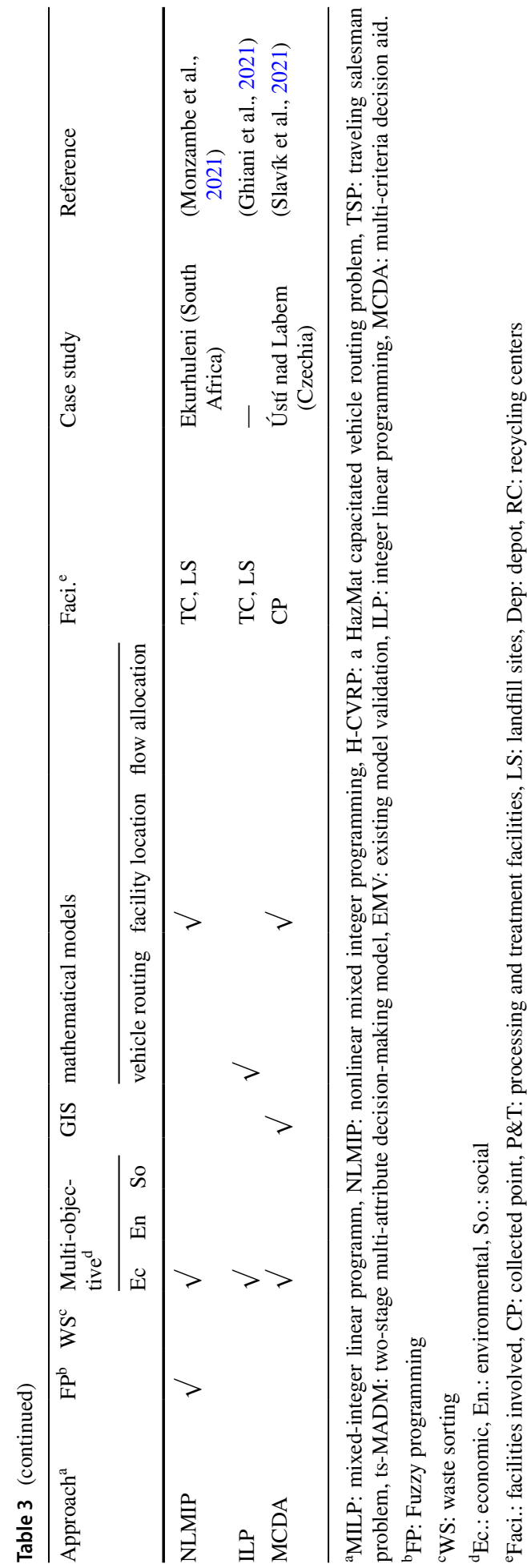




\subsection{Optimization of C\&T network}

The important features of studies related to optimizing the C\&T network over the past three years are highlighted in Table 3. Tracking hotspots and future directions of C\&T techniques through literature analysis, the following four points are summarized in this review. (i) The shift from single-objective to multi-objective analysis: from the beginning only to focus on the shortest route (Fiorucci et al., 2003), to the pursuit of the optimal vehicle routes and environmental effects (Ferronato et al., 2020; Hannan et al., 2020; Yousefloo \& Babazadeh, 2020), and then more studies involved social effects (Chabok et al., 2020; Yadav et al., 2020). Bányai et al. put forward a cyber-physical system that included routing, distribution, and scheduling issues to simulate the urban waste $\mathrm{C} \& \mathrm{~T}$ process, while minimizing overall operating costs and the environmental effects of $\mathrm{CO}_{2}$ emissions simultaneously (Bányai et al., 2019). Tirkolaee et al. presented a multiperiod model to resolve the green locationallocation-inventory problem under uncertainty, whose objective was to reduce economic costs and pollution emissions costs, including air, water, and soil pollution (Tirkolaee et al., 2020). However, compared to directly quantifying economic costs and $\mathrm{CO}_{2}$ emissions with numerical values, a unified social evaluation standard has not yet been formed, and it is difficult to compare and measure the social effects of various literature.

(ii) Multiple methods (algorithms) are combined to solve various models. As an operational research technique, MILP has become one of the most widely used modeling frameworks for C\&T network optimization. However, when it comes to nonlinear constrained optimization, such as regional roads and slopes, traffic congestion, source classification, it is frequently necessary to establish a NLMIP model. This model's solution is often limited by the algorithm's difficulty but lays the foundation for thorough research. With the rise of AI, the newly developed algorithm has been applied to C\&T optimization research. The literature review showed that frequently used AI systems for C\&T process modeling and optimization included ANN, genetic algorithm (GA), support vector machine (SVM), linear regression (LR), and decision tree (DT) (as shown in Fig. 2a). As mentioned above, modeling the C\&T optimization process involves multiple variables and might be difficult due to the nonlinear behavior exhibited by these variables. Owing to its innovative surge and ability to handle large data, map nonlinear relationships, and solve complex problems at high speed, ANN has gained superiority over other models in C\&T optimization modeling studies (Hoque \& Rahman, 2020). As shown in Fig. 2(b), an ANN typically consists of an input layer, hidden layers, and

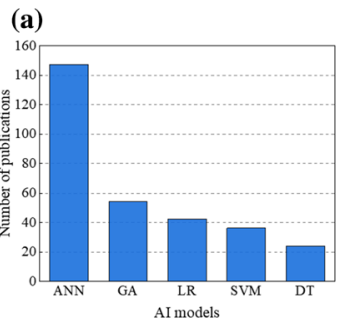

(b)

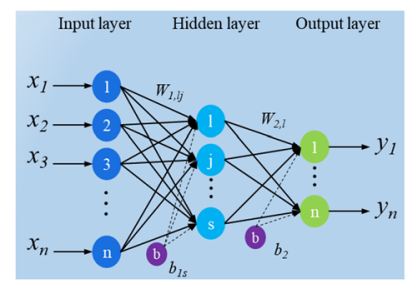

(c)

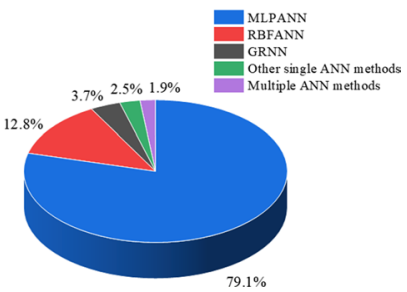

Fig. 2 Analytical data for ANN model. (a): Distribution of publications by AI model type. (b): Schematic diagram of the ANN model for optimization of C\&T network s ( $x$ : input value; $W$ : weight; $b$ : bias; $y$ : output value). (c): Proportions of different ANN methods in 147 studies. GRNN: generalized regression neural network 
an output layer, each of which consists of many nodes linked to each node in the following layers by directed weighted edges (Abdallah et al., 2020). It was reported that feedforward neural networks are the most dominant ANN approaches in studying MSWrelated issues (Xu et al., 2021). Analysis of 147 reviewed studies revealed that multilayer perceptron ANN (MLPANN) and radial basis function ANN (RBFANN) were the two most popular ANN methods, with MLPANN being used in $79 \%$ of the reviewed studies (Fig. 2c).

Besides, heuristic approaches have become popular as they can overcome huge data calculation problems under multiple constraints (Hannan et al., 2020). For instance, GA (Amal \& Chabchoub, 2018), simulated annealing algorithm (Men et al., 2019), backtracking search algorithm (Akhtar et al., 2017), and ant colony optimization (Tirkolaee et al., 2019) have been used for waste vehicle routing optimization. Nonetheless, when optimizing C\&T networks, heuristic algorithms (HA) have low precision and long execution time (Viotti et al., 2003). The meta-heuristic algorithm can overcome this shortcoming. Qiao et al. proposed a comprehensive benefit maximization scheme balancing economic, environmental, and social factors by a two-phase meta-heuristic algorithm combining particle swarm optimization and tabu search (Qiao et al., 2020), but it was not applied in the actual case. Besides, the p-median method (Lv et al., 2020), LCA (Taşkin \& Demir, 2020), saved footprint (Peri et al., 2018), voronoi graph (Xin et al., 2020) were also used for C\&T network optimization. Furthermore, GIS is often applied to optimize sustainable C\&T network in combination or alone (Chabok et al., 2020; Ferronato et al., 2020), because it can store, retrieve, analyze and apply large amounts of data, as well as the output visualization function with response time (Nguyen-Trong et al., 2017). On the other hand, GIS decisions are based on static analysis, unable to examine the effects of traffic congestion, waste production fluctuations, etc. It is also difficult to consider social acceptance. Therefore, GIS is often combined with other analytical methods, such as the analytic hierarchy process (AHP) (Ali \& Ahmad, 2020; Bouroumine et al., 2020; Chabok et al., 2020), MCDA (Slavík et al., 2021), and GA (Amal \& Chabchoub, 2018).

(iii) Research on the C\&T models of waste source separation. Due to mandatory source separation in Japan, the municipal department formulated a detailed schedule for collecting different MSW types and reminded residents through a smartphone application. For example, they collected combustible waste on Monday while collecting recyclable waste on Tuesday (Takahashi, 2020). Besides, the identification and classification for image analysis through neural networks contributed to the C\&T models of waste source separation (Nowakowski et al., 2020). Lou et al. proposed an optimal transportation model of various classified waste from the point of MSW generation to the final landfills through converting it to a modified TSP (Lou et al., 2020). However, the differences in classification policies make limited applicability of the published classification C\&T models.

(iv) The advance of smart device applications. With the popularization of the IoT and AI, monitoring the fill level and weight of waste in the smart bins is possible by radiofrequency identification (RFID) technology and GIS (Hannan et al., 2020; Owusu, 2020). Bányai et al. established a cyber-physical waste collection system by using Industry 4.0 technologies, as well as intelligent technologies (Bányai et al., 2019). The system was connected via WIFI to monitor the filling level of trash bins in real-time remotely and uploaded real-time data to the Waste Collection Cloud through RFID readers to optimize and adjust the C\&T route automatically. Simultaneously, the system can prioritize the collection order of different trash bins (Abdullah et al., 2018), which would phase out informal recyclers and scavengers (Lv et al., 2020). Meanwhile, the 5G wireless communication system can help connect smart bins to the cloud platform through the network and improve 
communication efficiency (Wang \& Nai, 2021). Furthermore, the routing system's optimization should consider combining the local social, geographic, topographical conditions, and even the residents around each collection point. It requires the system to be tested and optimized in practice, increasing the difficulty of wide applications (Hannan et al., 2020).

\section{Pretreatment techniques of MSW}

\subsection{Waste compaction and mechanical pretreatment}

Compaction is an effective pretreatment method to use pressure to decrease waste volume, improve treatment efficiency, and reduce GHG emissions (Chaerul \& Tompubolon, 2019), which can be performed in the collection bucket, transport vehicle, TS process and landfill. The unit weight of compacted waste depends on the composition of the waste, the layer thickness, the weight and type of compaction equipment, and the number of times the equipment passes through the waste. Nevertheless, waste with more than $25 \%$ plastic cannot be compacted (Okonta et al., 2017). As a mechanical pretreatment method of MSW, high-pressure extrusion has been applied to a host of waste treatment plants in Beijing (Kong et al., 2016). The high-pressure extrusion combined with friction heating, mixing, crushing, and shearing operations can realize the separation of organic fractions (Chen et al., 2010a). It promoted the hydrolysis of OFMSW and enhanced the methane production of anaerobic digestion (AD). However, an excessively high extrusion pressure would cause excessive acidification of the reactor (Xu et al., 2016). Autoclaving steam treatment and rotary drum reactor (RDR) are commonly used technologies in the MSW treatment industry. RDR can not only realize the fractionation of organic waste, but also be used as a pretreatment process for biological treatment (Gikas et al., 2018). Hansen et al. compared the pretreatment efficiency of three different mechanical pretreatment technologies of screw press, disk screen, and shredder with magnet on source-separated OFMSW: shredder with magnet $>$ spiral press $>$ disk screen (Hansen et al., 2007). In addition, dry waste dehydration, wet waste grinding, pulping/separation, degreasing, and other universal mechanical pretreatment methods all require the development of efficient and economical commercial techniques to enhance the potential for subsequent resource utilization.

\subsection{Waste sorting techniques}

The mixed or source-separated MSW transported to the TS will be further sorted to facilitate subsequent sorting treatment and resource utilization. At present, MSW sorting is still a combination of manual and automatic sorting and is gradually developing in AI, robot sorting, and multi-sensor fusion (Gundupalli et al., 2017; Pellegrinelli, 2019). Research on sorting techniques is a complement and alternative to source separation deficiencies. Common automatic sorting techniques are shown in Table 4. Bag breaking and crushing before sorting are essential. For example, Hong Kong used optical sensor technology to identify and classify green optical bags containing FW and then used hydraulically driven rollers to open light bags. After a crusher broke up the FW, the FW and optical bags were separated by screening (Woon \& Lo, 2016). In developing countries such as Iran, Brazil, and India, water separation based on buoyancy and gravity and mechanical separation using trommel screens, rotating drums, and shredders are the two commonly separated methods for OFMSW (Dehkordi et al., 2020). However, the water-separated system first needs to crush 


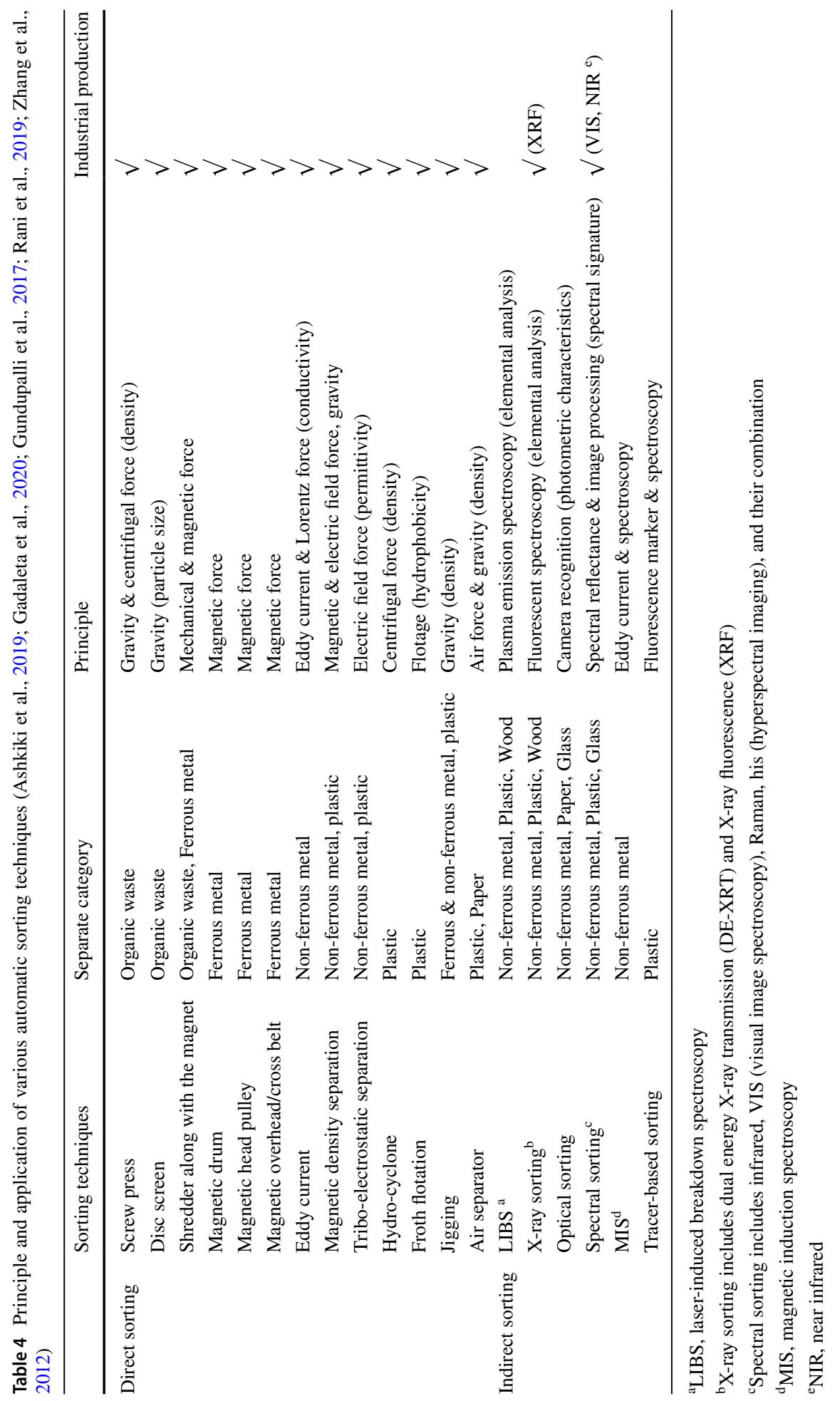


MSW with the assistance of a series of machines such as a shear shredder, hammer mill, ring mill, and disc mill, yet the water should be recycled (Zhang et al., 2012). Ashkiki et al. assessed the effects of seasonal changes and operating parameters on double-layer roller screens' performance in northern climates (Ashkiki et al., 2019), while there is no seasonal difference in the manual sorting of plastics (Gala et al., 2020). However, manual sorting should consider the impact on worker health.

The dynamic industrial application of sensor-based indirect automatic sorting techniques is currently studied (Signoret et al., 2020), especially for non-ferrous metal and plastic sorting. It is worth mentioning that the industrial identification system for waste sorting must identify the MSW on the high-speed conveyor belt within a few milliseconds; otherwise, the processor would not issue instructions to manipulate the robotic arm or compressed air nozzles for sorting operations. Some indirect sorting technologies such as XRF spectrometry, VIS, NIR have been used in factory production (Gadaleta et al., 2020); Rani et al. developed a compact and miniaturized NIR spectrometer and established a NIR spectrum database, which can sort all kinds of polymers well without pretreatments such as cleaning and drying (Rani et al., 2019). However, the sorting of black plastic waste, the interference of additives and fillers is still a challenge or a research direction. MidInfrared (MIR) can make up for the difficulty of sorting because the black waste plastic strongly absorbs the laser light from the NIR spectrometer (Signoret et al., 2019). Bae et al. compared the effects of Attenuated Total Reflectance (ATR) Fourier Transform Infrared Radiation (FTIR) and a Raman spectrometer in separating black plastic waste. Although the sorting results of FTIR-ATR were slightly better, the advantages of fast recognition and non-contact could arise the Raman spectrometer more competitive (Bae et al., 2019). Similarly, Signoret et al. investigated the separation effect of carbon black, calcite, talc, titanium oxide, and certain flame retardants as additives or fillers based on laboratory FTIR-ATR on plastic waste. However, it cannot be equated with commercially evaluating MIR-HSI (Signoret et al., 2020).

Recently, there have been studies on adding markers in plastic production to detect and sort traced objects, which have the advantages of maintaining plastics' appearance and mechanical properties. Brunner et al. identified waste polymers based on the incorporated fluorescent tracer, which could sort $300 \mathrm{~kg}$ of waste plastics per hour (Brunner et al., 2015). Fluorescence-labeled plastics can record significant fluorescence emission even after exposure to aggressive conditions (Arenas-Vivo et al., 2017). However, fluorescent substances must be marked on the surface and are easily interfered with by light-absorbing materials. Instead of optical tracers as tracking and identification markers, magnetic superparticles can overcome this problem (Müssig et al., 2019), but the environmental risks are caused by nanoparticles and microplastics that decompose after spilling into the environment are worthy of attention. Furthermore, as a method to identify the types of non-ferrous metals in mixed waste streams, MIS based on the eddy current can also avoid the defect of optical sorting, which is susceptibly affected by surface contaminants (O'Toole \& Peyton, 2019). Actually, in addition to the continued development or commercialization of sorting technology under factory acquisition's harsh conditions, the future of multi-sensor coupling for fine sorting, signal processing, and advanced classification algorithm also have excellent prospects. 


\subsection{Enhance the pretreatment strategy of bioconversion}

Recently, researchers were more interested in the bio-transformation of biodegradable OFMSW (kitchen waste, yard waste, garden waste, etc.) to produce value-added products (Sindhu et al., 2019). However, due to the inherent recalcitrance of the lignocellulosic biomass and the heterogeneity of OFMSW (Karthikeyan et al., 2017; Veluchamy \& Kalamdhad, 2017), hydrolysis limits the biotransformation efficiency (Bala et al., 2019). Substrate pretreatment is an effective strategy to improve the biodegradability of OFMSW before bioconversion (Kavitha et al., 2017), which can improve the water solubility of complex organic matter. In this process, microbial cells are damaged and lysed, lignin and hemicellulose are hydrolyzed to cleavage, cellulose crystallinity is decreased, and the complex molecules are broken down into simple monomers, then dissolved, and transferred to the water phase. The original pores of the material are amplified, and the porosity increases (Banu et al., 2020). It provides an enormous specific surface area for the attachment of microorganisms and enzymes in the subsequent biological treatment (Kannah et al., 2020). As shown in Fig. 3, after sorted OFMSW is crushed, solid-liquid separated, and conventional mechanical pretreated, other pretreatment methods are usually used to improve the biological treatment effect. As an expensive but indispensable step in OFMSW resource utilization, appropriate pretreatment or even combined pretreatment methods should be selected from multiple perspectives such as biomass substrate composition, subsequent biological treatment methods, and economic feasibility. Hence, research on new pretreatment techniques should focus on (1) increasing the yield of the target product, (2) accelerating the rate of biological reaction, (3) avoiding or reducing the generation of inhibitors/poisons, (4) convenient raw material management (i.e., transportation and storage), (5) environmental-friendly low energy consumption-stable operation (Carrere et al., 2016; Li et al., 2017; Panigrahi \& Dubey, 2019).
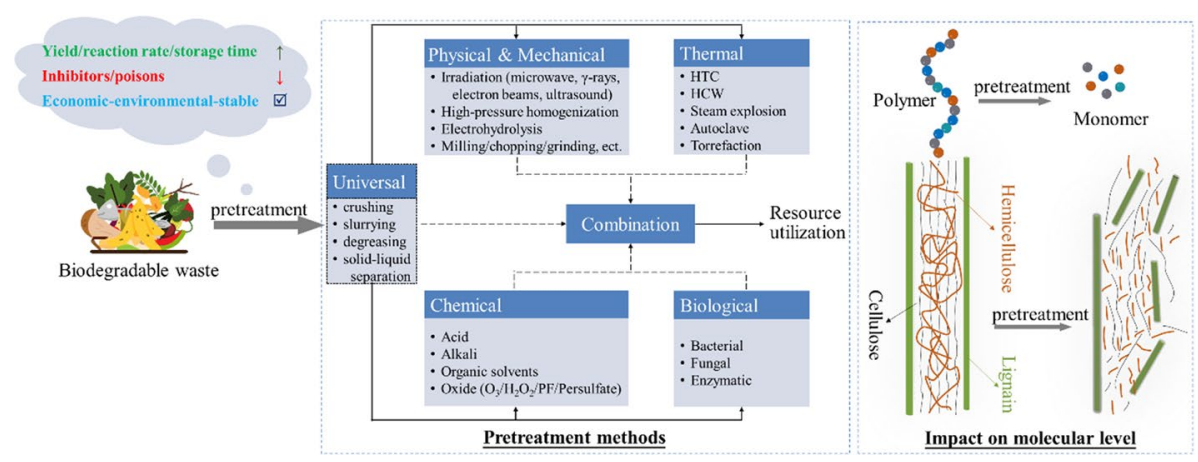

Fig. 3 Various pretreatment methods for biodegradable waste and impact on the molecular level (Bala \& Mondal, 2020; Banu et al., 2020; Córdova et al., 2019; El Gnaoui et al., 2020; Fang et al., 2020; Kannah et al., 2020; Liang et al., 2019; Yue et al., 2020) 


\section{Resource recovery and valorization}

The treatment and disposal are the end of the MSWM system and an essential step to achieving the recovery and valorization of MSW. In general, landfilling is the most convenient alternative to dispose of excess MSW. Although methane can be captured from landfills(Malav et al., 2020), high land demand, uncontrolled biogas quality and yield, high leachate concentrations, and the associated environmental pollution and human health issue make landfilling only a desperate and unsustainable option for the treatment of massive MSW temporarily. The pathways to resource MSW can be divided into mechanical recycling, thermal conversion, and biological strategies (Fig. 4). Notably, recycling is a broad concept. In parallel to the direct recovery of raw materials, energy recovery and value-added chemicals also fall under recycling.

\subsection{Mechanical recycling}

Recycling of MSW is an integral step toward a circular economy (Xiao et al., 2020a), and the low environmental footprint and energy consumption make recycling widely recognized as a sustainable waste management strategy (Faraca et al., 2019). Recycling is a systematic process, including collection, transportation, sorting, and reprocessing stages, and any missing link will make recycling uncompetitive (Ragaert et al., 2017). Due to the susceptibility of MSW to contamination, mechanical recovery (raw material recovery) is the preferred measure for recyclables such as paper, metal, plastic, and glass, but does not exclude energy recovery methods for combustible waste among them. In addition, informal recycling is a consolidated feature in MSWM streams of developing countries like Mexico, Brazil, China, and India (Conke, 2018). However, it is more targeted at MSW that generates economic benefits for waste collectors. Cooperation with municipalities, such as outsourcing, can transition from informal to formal recycling (Yousefloo \& Babazadeh, 2020). Furthermore, with the closure of some markets for recycled goods in China, the fate of recycled products in some developed countries is also forced to be rethought (Wang et al., 2019b).

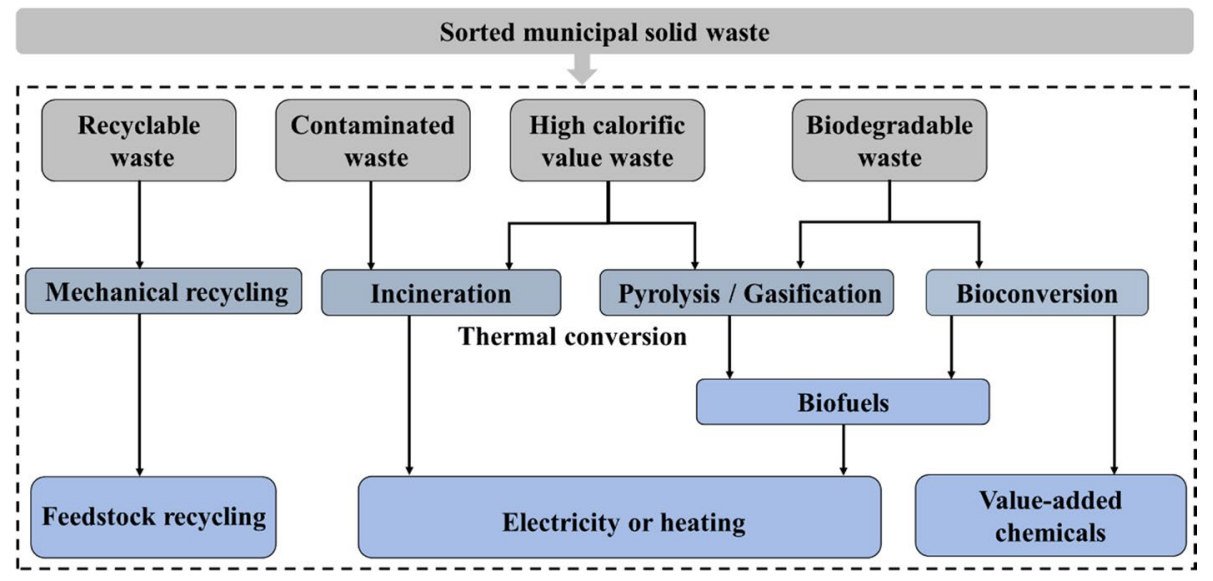

Fig. 4 Resource recovery methods and products of various MSW after sorting 


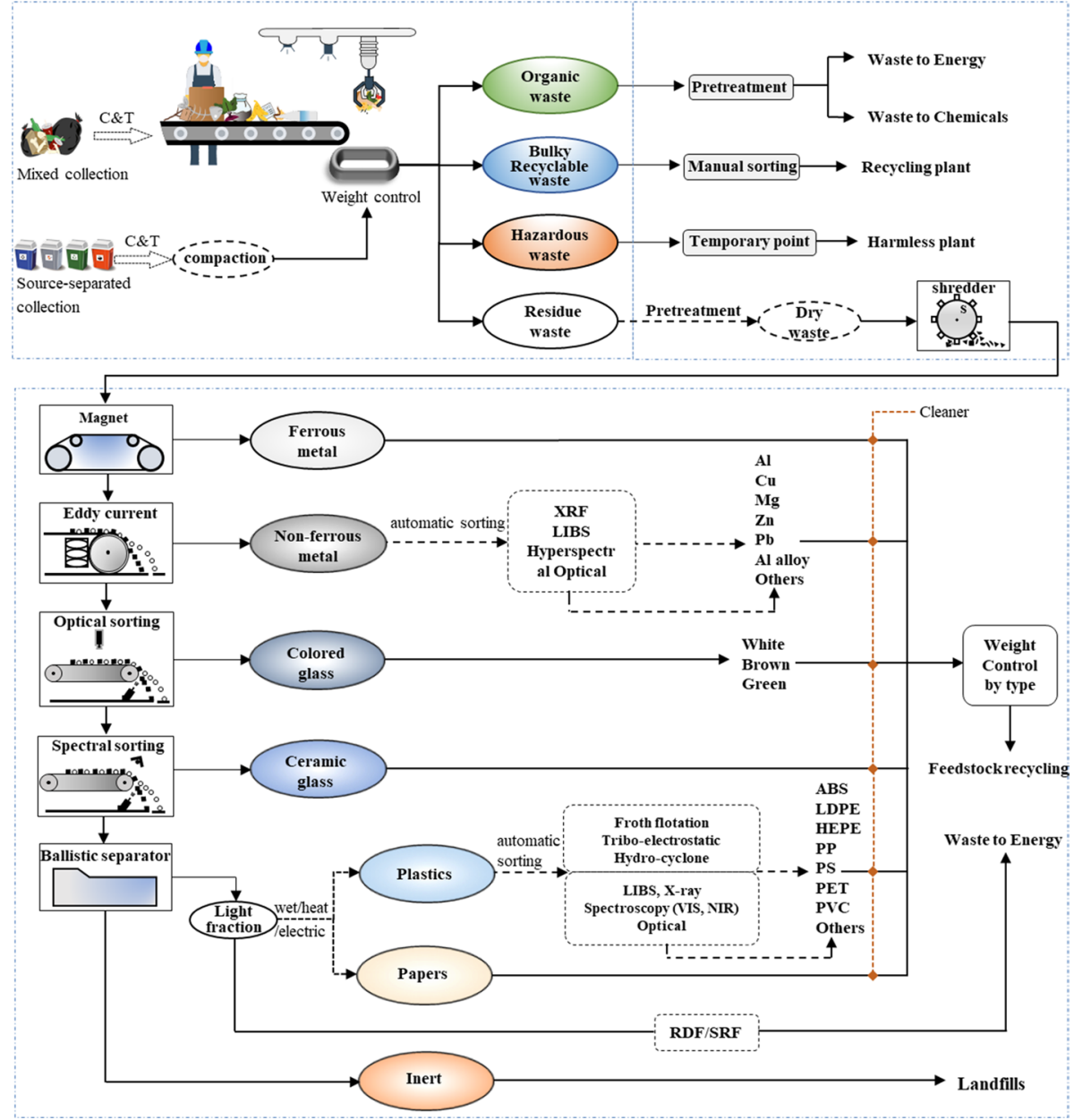

Fig. 5 Schematic of waste sorting and fine sorting techniques for recyclable MSW (Gundupalli et al., 2017; Vazquez et al., 2020; Wagland, 2019)

Source separation of MSW creates favorable conditions for recycling (Salah et al., 2020). Figure 5 illustrates the fine sorting of recyclable waste in two scenarios, based on source separation and mixed collection. After the manual or mechanical removal of organics, bulky recyclables (cardboard, plastic and glass bottles, bulky metals), and hazardous wastes, the residual waste is finely sorted by a combined method (magnetic separation, eddy current, optical sorting, etc.) for feedstock recovery. The purpose of cleaning is to remove surface pairs of contaminants/impurities to guarantee the recycled material quality, especially plastic wastes with high heterogeneity (Soto et al., 2020). In detail, the purity of plastic waste is the primary factor determining the quality and economic profitability of the recycled product (Faraca et al., 2019). The presence of impurities or heterogeneous plastics makes it challenging to realize the potential benefits of mechanical recycling, making thermal conversion seem more appropriate. Besides, bioplastics (BP) are an effective strategy to tackle white pollution due to their potential biodegradability and harmlessness (Shen 
et al., 2020). However, in the long run, BP is not a complete replacement for conventional plastics in terms of performance, and its share in the overall plastics market is relatively low. Therefore, mechanical recycling and reuse of plastics are currently reliable means of addressing white pollution (Borrelle et al., 2020).

From an environmental point of view alone, the "zero-waste" concept seeks higher or even $100 \%$ recycling rates. However, the reduced cost of primary materials makes new products made from recycled secondary materials uncompetitive (Pluskal et al., 2020), and the negative economic benefits of the entire recycling process are prohibitive. It is worthwhile for policymakers to consider whether it is necessary to invest a lot of labor and much money in detailed sorting to increase recycling rates (Cui \& Sošić, 2019). Therefore, it is not advisable to pursue a high recycling rate, but rather to find an appropriate balance between economic benefits and pollution emissions in MSWM system. Nevertheless, some of the difficult-to-measure metrics significantly aggravate the complexity of modeling. Besides, the "Internet + Recycling" associated with mobile applications offers a new approach to waste recycling management at the source (Gu et al., 2019).

\subsection{Thermal conversion}

Still, about $30 \%$ of residual MSW (e.g., contaminated paper and plastics) cannot be recovered even with advanced waste programs that separate recyclables from other MSW. The thermal conversion method of energy recovery is a promising alternative to landfills, including incineration, pyrolysis, gasification, and energy densification and homogenization techniques (such as refuse derived fuel (RDF), solid recovered fuel (SRF), and hydrothermal carbons (HTC)). The major advantage of thermal conversion is efficient MSW reduction, heat and material recovery in a short time, which is a promising waste-to-energy (WtE) technology (Sebastian et al., 2020), and more suitable for dry MSW with little or no moisture content (Kumar \& Samadder, 2017). Table 5 provides a detailed comparison of the three main thermal conversion methods. In those processes, the chemical bonds between the carbon, hydrogen, and oxygen atoms are broken, and substantial amounts of energy are released, which can then be used for energy recovery (electricity, heat) or for the production of gases, liquids, or solids known as biofuels to reduce dependence on fossil fuels. Now WtE concentrates on recovering heat for running steam engines to generate electricity or system heating. By the end of 2019, China had built $418 \mathrm{WtE}$ plants (Xu et al., 2020), whose total incineration capacity is even higher than the whole EU. Moreover, it is gratifying to note that recent studies, such as microwave heating acting on the material center, assisted co-pyrolysis of $\mathrm{CO}_{2}$ or additives, and catalytic pyrolysis paved the way for pyrolysis commercialization (Lu et al., 2020; Zhang et al., 2020b). Nevertheless, there were still limited engineering applications for MSW synergistic pyrolysis. Plasmaassisted gasification using a plasma torch as a heat source $\left(5000{ }^{\circ} \mathrm{C}\right.$ ) (Rajasekhar et al., 2015), higher syngas yields, and lower toxic accumulation are considered as an emerging and promising technology; however, it has not yet gained acceptance in MSW processing (Mukherjee et al., 2020).

Compared to gasification and pyrolysis, mixed-collection waste is more suitable for incineration. However, an intensive pretreatment phase is indispensable to eliminate excessive moisture, inert waste, and toxic elements such as chlorine and mercury (Lombardi et al., 2015). Incineration of OFMSW has been reported, but OFMSW alone (e.g., FW) is not an appropriate incineration option, and co-incineration with other wastes loses the significance of waste sorting. Besides, incineration is the preferred decontamination method 


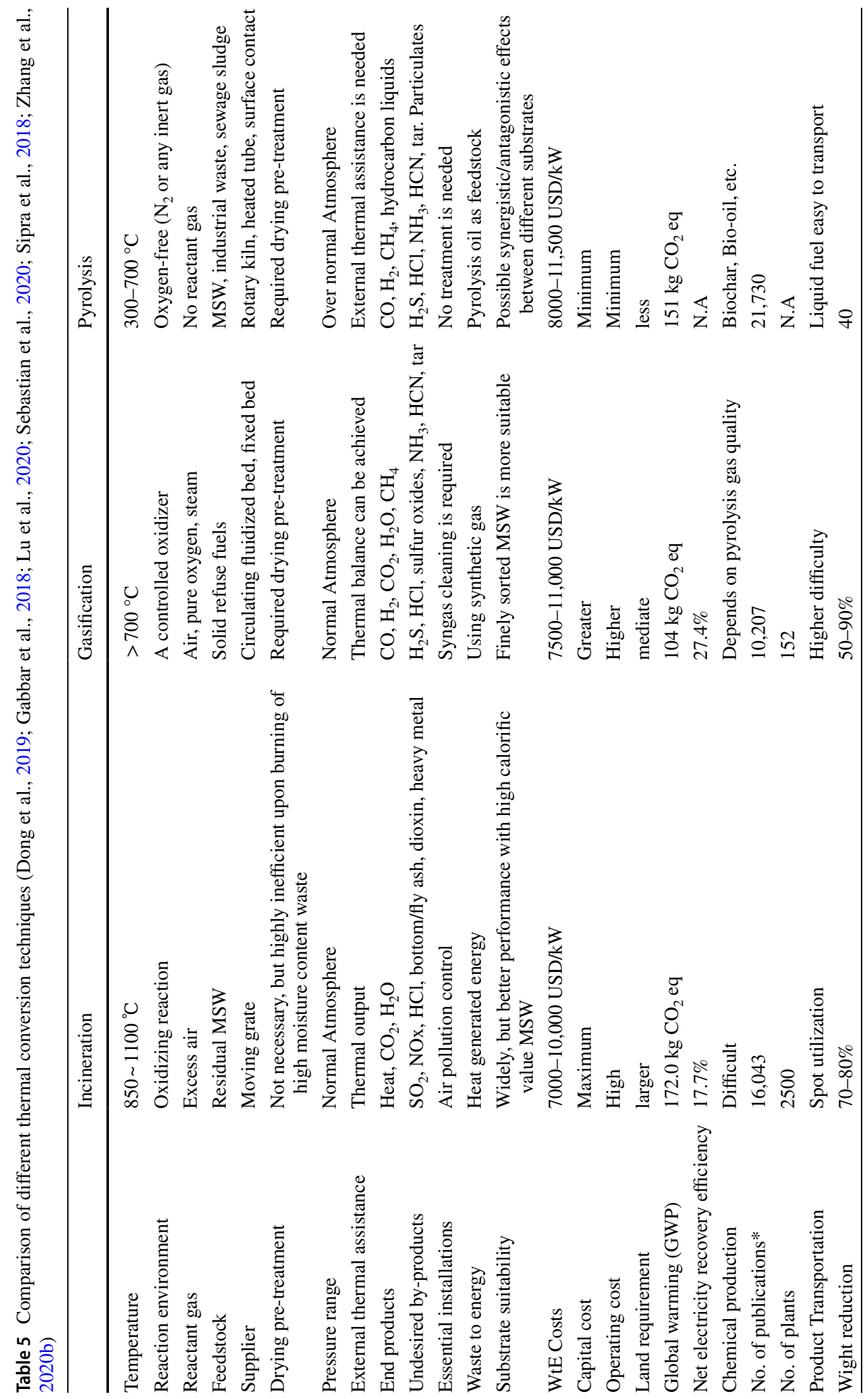




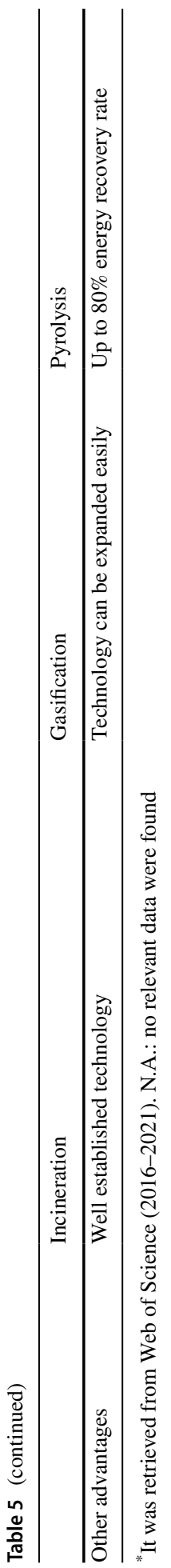


for a tremendous amount of intractable or infectious waste (e.g., medical waste contaminated with COVID-19) generated each year. Pyrolysis possesses strong substrate adaptability, and most carbon-containing wastes such as waste plastics (Liu et al., 2020), waste tires (Arabiourrutia et al., 2020), OFMSW (Elkhalifa et al., 2019), agroforestry waste (Kan et al., 2016), and even sewage sludge could be used in the pyrolysis process. Meanwhile, the respective intermediates produced by the mixed MSW during the pyrolysis process may interact with each other, to cause synergistic pyrolysis (desired by the researchers): it may accelerate the reaction rate or increase the yield of the desired fuel product (Lu et al., 2020; Wang et al., 2019a). For example, the co-pyrolysis of FW with other MSW (e.g., PVC, PET) has not only significant synergistic effects but improved product quality (Qureshi et al., 2020; Tang et al., 2018). In contrast, pyrolysis seems to be a better option than gasification for the cellulose-rich OFMSW. Gasification is highly influenced by MSW properties and less adaptable to mixed wastes, so that most mainstream gasification technologies typically use pretreated waste or waste-derived fuel as feedstock rather than the initial waste (Schulze et al., 2017). In addition, combined pyrolysis gasification, which uses pyrolysis products as gasification feedstock, will be a promising option for small urban waste treatment plants.

The prevailing trend in thermal conversion technology is to optimize MSW feedstocks and decrease transportation expenses through energy densification treatment steps (Mukherjee et al., 2020), such as RDF, SRF, HTC. As a homogeneous fuel with a high calorific value (1912-3346 kcal/kg) (Malav et al., 2020), RDF/SRF can significantly reduce GHG emissions due to its partial carbon neutrality, but is not suitable for high moisture OFMSW. HTC offers significant advantages for pretreatment of high moisture OFMSW (e.g., FW). Therefore, in selecting an appropriate WtE process, its economics and environmental applicability should be evaluated on a whole life cycle basis, rather than being limited to a particular technology (Torkashvand et al., 2021).

\subsection{Bioconversion strategies}

Bioconversion strategies are based on anaerobic/aerobic microorganisms' physiological functions, and the connection/integration of environmental biotechnologies to sustainably bioconvert OFMSW with high water content into valuable products through different conversion pathways. It offers economic advantages and eliminates the nuisance generated by the decomposition of organic waste in the surroundings and landfills (Bilal \& Iqbal, 2019). Bioconversion strategies for wet waste have already been reviewed in detail (Engelberth, 2020; Melikoglu, 2020; Sindhu et al., 2019), so that this review would analyze the latest bioconversion strategies from a product perspective, (1) Biofuels: including gaseous biofuels (hydrogen, methane, and biohythane), liquid fuels (ethanol, butanol, biodiesel), and microbial fuel cells; (2) value-added chemicals: including liquid chemicals (organic acids such as volatile fatty acids (VFAs), medium-chain and long-chain fatty acids, lactic acid, citric acid, etc.; biosurfactants; sugars such as glucose, D-tagatose, D-mannose, etc.; bioactive compounds such as antioxidants, pigments, polysaccharides, polyphenols, etc.) and solid chemicals (polyhydroxyalkanoate (PHA), active peptides, bioproteins, snow melting agents, bio-compost and bio-feeds, etc.).

Green biofuels are a promising alternative to fossil fuels, contributing significantly to environmental, economic, and social sustainability (Kammen \& Sunter, 2016). Dark fermentation without light has engineering advantages over photo fermentation, which is notoriously difficult to penetrate consistently with sunlight (Hassan et al., 2020). Wannapokin 
et al. proposed a new method of co-immobilizing nanometals with hydrogen-producing microorganisms and obtained better hydrogen production performance (Wannapokin et al., 2020), but it is debatable whether the method is suitable for large-scale industrial production. Co-fermentation with complementary substrates and synergistic approaches that combine biological strategies with electrochemistry promise sustainable technologies. For example, Zhi et al. integrated a microbial electrolytic cell into a conventional AD system to electrochemically regulate the co-fermentation of FW and sewage sludge, which stimulated the auto-fermentation and proliferation of typical methanogenic bacteria and increased $\mathrm{CH}_{4}$ yields by 2.8 times (Zhi et al., 2019). In addition, attention should be paid to the efficient separation and utilization of the generated biofuels.

Various value-added chemicals synthesized by OFMSW are more advantageous in unit price than biofuels. Compared with the latest market price (Sep. 2021, USD/ton): poly(3hydroxybutyrate-co-3-hydroxyvalerate) (PHBV) (9000) $>$ calcium magnesium acetate snow melting agent $(2000)>$ citric acid (1320) $>$ propionic acid (1164) $>$ ethanol (1035) $>$ acetic acid (935), with the price of ethanol increasing due to the effects of COVID-19. They can be used not only as specialty chemicals that can enhance specific properties or functions of other products but also as niche chemicals for target specific industries or markets (Xiong et al., 2019). For instance, VFAs are not only important intermediates in bioconversion processes to generate hydrogen, methane, and PHA, but are also excellent chemical feedstocks through matrix separation. However, some researchers used a single category of FW as a substrate, such as citrus peel waste (Patsalou et al., 2017) and coffee grounds (Gu et al., 2020). Extremely heterogeneous OFMSW are not easily reproducible for experimental results. In addition, the platform for microbial consortium construction provides new perspectives for the high-value utilization of OFMSW. For example, Shahab et al. inoculated aerobic fungus, facultative anaerobic lactic acid bacteria, and anaerobic product-forming strains of fermented lactic acid on a membrane-aerated bioreactor based on oxygen gradients, respectively, to modularize microbial functions and establish a lactate platform for high-value conversion of complex substrates (Shahab et al., 2020). Therefore, biorefining of OFMSW is environmentally comparable with state-of-the-art incinerators, but faces the following challenges: (1) the complexity of MSW sources and composition makes the treatment of actual waste by pure microorganisms not economically feasible (Krishnan et al., 2019), requiring high pretreatment costs; (2) more extended processing footprint brings more operating costs; (3) low yields and high complexity of product separation; and (4) the reduction effect of waste is not apparent, and the disposal of by-products must be considered.

In summary, the treatment of MSW in categories according to their characteristics is intended to realize environmental and economic benefits with minimal investment and operating costs. However, they are not isolated from each other but are interconnected and mutually reinforcing. For example, the pyrolysis product biochar can stimulate direct interspecies electron transfer between the syntrophic acetogen and methanogen communities as an electron conductor in the AD process and enhance methane production (Qiu et al., 2019). Zhao et al. added the landfill degradation product aged waste to the OFMSW anaerobic fermentation process, which increased the yield of short-chain fatty acid by 1.9 times. "Separate processing of sorted MSW + combining (intermediate) products from other processes or energy input to increase yield" may be a prospective approach for resource utilization of MSW in the future. 


\section{Conclusion and perspective}

Waste sorting has become a consensus among policymakers. The recovery of energy and resources not only creates an opportunity to expand the 'zero waste' concept but also provides financial support for the whole process of MSWM. Because the critical issues of waste management are interconnected and interact, this paper has the benefit of providing a systematic and unified overview of MSW from generation, sorting, C\&T, pretreatment, to resource recovery. However, there is no one-size-fits-all management strategy, and it is essential to develop a nationally/regionally appropriate MSWM system, beginning at the source. Although the pursuit of 'zero waste' will be an essential direction to move forward, it is imperative to establish a network of sorted MSW, which can be resourced simultaneously, to provide the most appropriate technology options for each MSW type. Here are some summaries and prospects:

1. GDP per capita is the dominant factor influencing the generation and composition of MSW; however, it may also depend on other factors such as dietary culture in China. Further valid data on MSW generation and composition need to be supplemented to develop predictive models for artificial intelligence-based tools.

2. Source separation compensates for the inaccurate classification of mixed waste. Sustainable source-separated strategies require building on a complete waste management stream, and system technology development will be an essential adjunct to enhanced source separation. Moreover, to realize the fine sorting of recyclable materials, MSW with source separation may still require further sorting after C\&T. With the emergence of sensor-based sorting technologies, it is still unknown whether the future will be a complex quadruple sort (e.g., Shanghai), an organic/inorganic dichotomy, or a mixed collection method. What is clear, however, is that source separation reduces MSW cross-contamination and can significantly increase the fraction of MSW available for mechanical recycling.

3. Pretreatment processes are an indispensable part of achieving efficient resource recovery. However, the development of technologies such as fine sorting is still promising in source separation.

4. The uniformity of the C\&T process management also allows for improving the quality of the MSWM system. The optimization of C\&T network would prioritize transportation costs and also focus on carbon emissions and social impact. The investments in smart devices and AI provide the possibility to implement C\&T models for source separation.

5. Mechanical recycling is a sustainable means of achieving multiple recyclable MSW reuses, but incineration is undoubtedly the preferred option for contaminated MSW (including medical waste). Pyrolysis and gasification as indirect WtE technologies, offer new ideas for chemical recycling. OFMSW is adapted to bioconversion, yet strongly relies on pre-treatment (physical, chemical, thermal, biological, and combined). Biorefining is a promising approach for the synthesis of various value-added products; however, due to the heterogeneity of OFMSW, it is not straightforward to obtain the target products.

6. AI, IoT, and 5G technologies will be widely and deeply used for waste generation prediction, waste collection route optimization, waste management facility positioning, and waste resource recovery process modeling, etc. MSWM will also enter a leapfrog development stage. 
7. MSWM system is a tightly interconnected network system. One treatment unit is likely to provide energy, substrates, or promoters that can be used to boost the capacity for another treatment unit to increase the overall profitability of the overall MSWM. It takes the combined efforts of scientists and engineers to develop overall supply and demand chains that can value MSW both technically and economically to achieve sustainable MSWM. Balancing system costs, environmental effects, and social impacts have always been a concern for MSWM. Unfortunately, due to the uncertainty of C\&T and resourceization process selection, this paper does not evaluate the economic and environmental perspectives, which requires a complete life-cycle evaluation of each pathway, which will be worth considering in the future as each technology becomes commercially viable.

Author's contributions $\mathrm{XMZ}$ and YGC conceived and designed the structure of manuscript. XMZ, CL, and YXC collected the data. XMZ and CL wrote the paper. XMZ, GHZ, and YGC reviewed and edited the manuscript. All authors read and approved the final manuscript.

Funding This work was supported by the National Key Research and Development Program Project of China (Grant No. 2019YFC1906301).

Data availability The data supporting this review are from previously reported studies, which have been cited in this manuscript.

\section{Declarations}

Conflict of interest The authors declared that there is no conflict of interest.

\section{References}

Abbasi, M., \& El Hanandeh, A. (2016). Forecasting municipal solid waste generation using artificial intelligence modelling approaches. Waste Management, 56, 13-22. https://doi.org/10.1016/j.wasman.2016. 05.018

Abdallah, M., Talib, M. A., Feroz, S., Nasir, Q., Abdalla, H., \& Mahfood, B. (2020). Artificial intelligence applications in solid waste management: A systematic research review. Waste Management, 109, 231-246. https://doi.org/10.1016/j.wasman.2020.04.057

Abdullah, N., Alwesabi, O.A., \& Abdullah, R. (2018) IoT-based smart waste management system in a smart city, pp. 364-371, Springer. https://doi.org/10.1007/978-3-319-99007-1_35

Abylkhani, B., Aiymbetov, B., Yagofarova, A., Tokmurzin, D., Venetis, C., Poulopoulos, S., Sarbassov, Y., \& Inglezakis, V. J. (2019). Seasonal characterisation of municipal solid waste from Astana city, Kazakhstan: Composition and thermal properties of combustible fraction. Waste Management \& Research, 37(12), 1271-1281. https://doi.org/10.1177/0734242X19875503

Adelodun, B., Kim, S. H., \& Choi, K.-S. (2021). Assessment of food waste generation and composition among Korean households using novel sampling and statistical approaches. Waste Management, 122, 71-80. https://doi.org/10.1016/j.wasman.2021.01.003

Agency, U.S.E.P. (2016). Municipal Solid Waste.

Akhtar, M., Hannan, M., Begum, R., Basri, H., \& Scavino, E. (2017). Backtracking search algorithm in CVRP models for efficient solid waste collection and route optimization. Waste Management, 61, 117-128. https://doi.org/10.1016/j.wasman.2017.01.022

Ali, S. A., \& Ahmad, A. (2020). Suitability analysis for municipal landfill site selection using fuzzy analytic hierarchy process and geospatial technique. Environmental Earth Sciences, 79, 227. https://doi.org/ $10.1007 / \mathrm{s} 12665-020-08970-\mathrm{z}$ 
Amal, L., \& Chabchoub, H. (2018). SGA: Spatial GIS-based genetic algorithm for route optimization of municipal solid waste collection. Environmental Science and Pollution Research, 25(27), 2756927582. https://doi.org/10.1007/s11356-018-2826-0

Amodeo, C., Hattou, S., Buffière, P., \& Benbelkacem, H. (2021). Temperature phased anaerobic digestion (TPAD) of organic fraction of municipal solid waste (OFMSW) and digested sludge (DS): Effect of different hydrolysis conditions. Waste Management, 126, 21-29. https://doi.org/10.1016/j.wasman. 2021.02.049

Andersson, C., \& Stage, J. (2018). Direct and indirect effects of waste management policies on household waste behaviour: The case of Sweden. Waste Management, 76, 19-27. https://doi.org/10.1016/j.wasman.2018.03.038

Aphale, O., Thyberg, K. L., \& Tonjes, D. J. (2015). Differences in waste generation, waste composition, and source separation across three waste districts in a New York suburb. Resources, Conservation and Recycling, 99, 19-28. https://doi.org/10.1016/j.resconrec.2015.03.008

Arabiourrutia, M., Lopez, G., Artetxe, M., Alvarez, J., Bilbao, J., \& Olazar, M. (2020). Waste tyre valorization by catalytic pyrolysis-A review. Renewable and Sustainable Energy Reviews, 129, 109932. https://doi.org/10.1016/j.rser.2020.109932

Arenas-Vivo, A., Beltran, F., Alcazar, V., de la Orden, M., \& Urreaga, J. M. (2017). Fluorescence labeling of high density polyethylene for identification and separation of selected containers in plastics waste streams. Comparison of thermal and photochemical stability of different fluorescent tracers. Materials Today Communications, 12, 125-132. https://doi.org/10.1016/j.mtcomm.2017.07.008

Ashani, P. N., Shafiei, M., \& Karimi, K. J. B. T. (2020). Biobutanol production from municipal solid waste: Technical and economic analysis. Bioresource Technology, 308, 123267. https://doi.org/10.1016/j. biortech.2020.123267

Ashkiki, A. R., Felske, C., \& McCartney, D. (2019). Impacts of seasonal variation and operating parameters on double-stage trommel performance. Waste Management, 86, 36-48. https://doi.org/10.1016/j.wasman.2019.01.026

Bae, J.-S., Oh, S.-K., Pedrycz, W., \& Fu, Z. (2019). Design of fuzzy radial basis function neural network classifier based on information data preprocessing for recycling black plastic wastes: Comparative studies of ATR FT-IR and Raman spectroscopy. Applied Intelligence, 49(3), 929-949. https://doi.org/ 10.1007/s10489-018-1300-5

Bala, R., Gautam, V., \& Mondal, M. K. (2019). Improved biogas yield from organic fraction of municipal solid waste as preliminary step for fuel cell technology and hydrogen generation. International Journal of Hydrogen Energy, 44(1), 164-173. https://doi.org/10.1016/j.ijhydene.2018.02.072

Bala, R., \& Mondal, M. K. (2020). Study of biological and thermo-chemical pretreatment of organic fraction of municipal solid waste for enhanced biogas yield. Environmental Science and Pollution Research, 27(22), 27293-27304. https://doi.org/10.1007/s11356-019-05695-w

Banu, J. R., Merrylin, J., Usman, T. M. M., Kannah, R. Y., Gunasekaran, M., Kim, S.-H., \& Kumar, G. (2020). Impact of pretreatment on food waste for biohydrogen production: A review. International Journal of Hydrogen Energy, 45(36), 18211-18225. https://doi.org/10.1016/j.ijhydene.2019.09.176

Bányai, T., Tamás, P., Illés, B., Stankevičiūtè, Ž, \& Bányai, Á. (2019). Optimization of municipal waste collection routing: Impact of industry 4.0 technologies on environmental awareness and sustainability. International Journal of Environmental Research and Public Health, 16(4), 634. https://doi.org/10. 3390/ijerph16040634

Benis, K. Z., Safaiyan, A., Farajzadeh, D., Nadji, F. K., Shakerkhatibi, M., Harati, H., Safari, G., \& Sarbazan, M. (2019). Municipal solid waste characterization and household waste behaviors in a megacity in the northwest of Iran. International Journal of Environmental Science and Technology, 16(8), 4863-4872. https://doi.org/10.1007/s13762-018-1902-9

Bilal, M., \& Iqbal, H. M. (2019). Sustainable bioconversion of food waste into high-value products by immobilized enzymes to meet bio-economy challenges and opportunities-A review. Food Research International, 123, 226-240. https://doi.org/10.1016/j.foodres.2019.04.066

Boies, A., Hankey, S., Kittelson, D., Marshall, J. D., Nussbaum, P., Watts, W., \& Wilson, E. J. (2009). Reducing motor vehicle greenhouse gas emissions in a non-California state: A case study of Minnesota. Environmental Science \& Technology, 43(23), 8721-8729. https://doi.org/10.1021/es902019z

Borrelle, S. B., Ringma, J., Law, K. L., Monnahan, C. C., Lebreton, L., McGivern, A., Murphy, E., Jambeck, J., Leonard, G. H., \& Hilleary, M. A. (2020). Predicted growth in plastic waste exceeds efforts to mitigate plastic pollution. Science, 369(6510), 1515-1518. https://doi.org/10.1126/science.aba3656

Bouroumine, Y., Bahi, L., Ouadif, L., Elhachmi, D., \& Errouhi, A.A. (2020). Sitting MSW Landfill Combining GIS and Analytic Hierarchy Process (AHP), Case Study: Ajdir, Morocco. International Journal of Advanced Research in Engineering and Technology, 11(5), 318-328. https://doi.org/10.34218/ IJARET.11.5.2020.033 
Brunner, S., Fomin, P., \& Kargel, C. (2015). Automated sorting of polymer flakes: Fluorescence labeling and development of a measurement system prototype. Waste Management, 38, 49-60. https://doi.org/ 10.1016/j.wasman.2014.12.006

BSD, (2013). Municipal waste management in Berlin. Berlin Senate Department for Urban Development and the Environment Communication.

Bulatov, N. K., Toilybayev, A. E., Suleyeva, N. Z., \& Sarzhanov, D. K. (2021). Development of the model (algorithm) of the efficient transportation logistics with the purpose of collection and transportation of the solid municipal waste to the places of their recycling. Environment, Development and Sustainability, 23(2), 2015-2037. https://doi.org/10.1007/s10668-020-00661-w

Calabro, P., \& Satira, A. (2020). Recent advancements towards resilient and sustainable municipal solid waste collection systems. Current Opinion in Green and Sustainable Chemistry, 26, 100375. https:// doi.org/10.1016/j.cogsc.2020.100375

Carrere, H., Antonopoulou, G., Affes, R., Passos, F., Battimelli, A., Lyberatos, G., \& Ferrer, I. (2016). Review of feedstock pretreatment strategies for improved anaerobic digestion: From lab-scale research to full-scale application. Bioresource Technology, 199, 386-397. https://doi.org/10.1016/j. biortech.2015.09.007

Cetin, M. (2013) Advances in landscape architecture, IntechOpen.

Cetin, M. (2015a). Chapter 55: Using recycling materials for sustainable landscape planning, environment and ecology at the beginning of 21 st century. Kliment Ohridski University Press, Sofia.

Cetin, M. (2015b). Consideration of permeable pavement in landscape architecture. Journal of Environmental Protection and Ecology, 16(1), 385-392.

Chabok, M., Asakereh, A., Bahrami, H., \& Jaafarzadeh, N. O. (2020). Selection of MSW landfill site by fuzzy-AHP approach combined with GIS: Case study in Ahvaz Iran. Environmental Monitoring and Assessment, 192(7), 1-15. https://doi.org/10.1007/s10661-020-08395-y

Chaerul, M., \& Tompubolon, G. (2019) The role of waste compaction facility for reducing greenhouse gasses emission of waste transportation, p. 012050, IOP Publishing.

Chen, D., Guo, Y., Huang, R., Lu, Q., \& Huang, J. (2010a). Pretreatment by ultra-high pressure explosion with homogenizer facilitates cellulase digestion of sugarcane bagasses. Bioresource Technology, 101(14), 5592-5600. https://doi.org/10.1016/j.biortech.2010.02.003

Chen, S., Huang, J., Xiao, T., Gao, J., Bai, J., Luo, W., \& Dong, B. (2020). Carbon emissions under different domestic waste treatment modes induced by garbage classification: Case study in pilot communities in Shanghai China. Science of the Total Environment, 717, 137193. https://doi.org/10.1016/j.scito tenv.2020.137193

Chen, X., Geng, Y., \& Fujita, T. (2010b). An overview of municipal solid waste management in China. Waste Management, 30(4), 716-724. https://doi.org/10.1016/j.wasman.2009.10.011

Chen, Y., Zhang, X., \& Chen, Y. (2021). Propionic acid-rich fermentation (PARF) production from organic wastes: A review. Bioresource Technology. https://doi.org/10.1016/j.biortech.2021.125569

Chester, M., Martin, E., \& Sathaye, N. (2008). Energy, greenhouse gas, and cost reductions for municipal recycling systems. Environmental Science \& Technology, 42(6), 2142-2149. https://doi.org/10.1021/ es0713330

Chifari, R., Piano, S. L., Matsumoto, S., \& Tasaki, T. (2017). Does recyclable separation reduce the cost of municipal waste management in Japan? Waste Management, 60, 32-41. https://doi.org/10.1016/j. wasman.2017.01.015

Conke, L. S. (2018). Barriers to waste recycling development: Evidence from Brazil. Resources, Conservation \& Recycling, 134, 129-135. https://doi.org/10.1016/j.resconrec.2018.03.007

Córdova, O., Passos, F., \& Chamy, R. (2019). Enzymatic Pretreatment of Microalgae: Cell Wall Disruption, Biomass Solubilisation and Methane Yield Increase. Applied Biochemistry and Biotechnology, 189(3), 787-797. https://doi.org/10.1007/s12010-019-03044-8

Cui, H., \& Sošić, G. (2019). Recycling common materials: Effectiveness, optimal decisions, and coordination mechanisms. European Journal of Operational Research, 274(3), 1055-1068. https://doi.org/10. 1016/j.ejor.2018.11.010

Dehkordi, S. M. M. N., Jahromi, A. R. T., Ferdowsi, A., Shumal, M., \& Dehnavi, A. (2020). Investigation of biogas production potential from mechanical separated municipal solid waste as an approach for developing countries (case study: Isfahan-Iran). Renewable and Sustainable Energy Reviews, 119, 109586. https://doi.org/10.1016/j.rser.2019.109586

Ding, Y., Zhao, J., Liu, J. W., Zhou, J., Cheng, L., Zhao, J., Shao, Z., Iris, Ç., Pan, B., Li, X., \& Hu, Z. T. (2021). A review of China's municipal solid waste (MSW) and comparison with international regions: Management and technologies in treatment and resource utilization. Journal of Cleaner Production, 293, 126144. https://doi.org/10.1016/j.jclepro.2021.126144 
Dong, J., Tang, Y., Nzihou, A., \& Chi, Y. (2019). Key factors influencing the environmental performance of pyrolysis, gasification and incineration Waste-to-Energy technologies. Energy Conversion \& Management, 196, 497-512. https://doi.org/10.1016/j.enconman.2019.06.016

Ebikade, E., Athaley, A., Fisher, B., Yang, K., Wu, C., Ierapetritou, M. G., \& Vlachos, D. G. (2020). The future is garbage: Repurposing of food waste to an integrated biorefinery. ACS Sustainable Chemistry \& Engineering, 8(22), 8124-8136. https://doi.org/10.1021/acssuschemeng.9b07479

Ebrahimian, F., \& Karimi, K. (2020). Efficient biohydrogen and advanced biofuel coproduction from municipal solid waste through a clean process. Bioresource Technology, 300, 122656. https://doi.org/ 10.1016/j.biortech.2019.122656

Echegaray, F., \& Hansstein, F. V. (2017). Assessing the intention-behavior gap in electronic waste recycling: The case of Brazil. Journal of Cleaner Production, 142, 180-190. https://doi.org/10.1016/j.jclepro. 2016.05.064

El Gnaoui, Y., Karouach, F., Bakraoui, M., Barz, M., \& El Bari, H. (2020). Mesophilic anaerobic digestion of food waste: Effect of thermal pretreatment on improvement of anaerobic digestion process. Energy Reports, 6, 417-422. https://doi.org/10.1016/j.egyr.2019.11.096

Elkhalifa, S., Al-Ansari, T., Mackey, H. R., \& McKay, G. (2019). Food waste to biochars through pyrolysis: A review. Resources, Conservation \& Recycling, 144, 310-320. https://doi.org/10.1016/j.resconrec. 2019.01.024

Engelberth, A. S. (2020). Evaluating economic potential of food waste valorization: Onward to a diverse feedstock biorefinery. Current Opinion in Green and Sustainable Chemistry, 26, 100385. https://doi. org/10.1016/j.cogsc.2020.100385

Fan, B., Yang, W., \& Shen, X. (2019). A comparison study of 'motivation-intention-behavior'model on household solid waste sorting in China and Singapore. Journal of Cleaner Production, 211, 442-454. https://doi.org/10.1016/j.jclepro.2018.11.168

Fang, S., Lin, Y., Lin, Y., Chen, S., Shen, X., Zhong, T., Ding, L., \& Ma, X. (2020). Influence of ultrasonic pretreatment on the co-pyrolysis characteristics and kinetic parameters of municipal solid waste and paper mill sludge. Energy, 190, 116310. https://doi.org/10.1016/j.energy.2019.116310

Faraca, G., Martinez-Sanchez, V., \& Astrup, T. F. (2019). Environmental life cycle cost assessment: Recycling of hard plastic waste collected at Danish recycling centres. Resources, Conservation \& Recycling, 143, 299-309. https://doi.org/10.1016/j.resconrec.2019.01.014

Fauziah, S. H., \& Agamuthu, P. (2012). Trends in sustainable landfilling in Malaysia, a developing country. Waste Management \& Research, 30(7), 656-663. https://doi.org/10.1177/0734242X12437564

Ferronato, N., Preziosi, G., Portillo, M. A. G., Lizarazu, E. G. G., \& Torretta, V. (2020). Assessment of municipal solid waste selective collection scenarios with geographic information systems in Bolivia. Waste Management, 102, 919-931. https://doi.org/10.1016/j.wasman.2019.12.010

Fiorucci, P., Minciardi, R., Robba, M., \& Sacile, R. (2003). Solid waste management in urban areas: Development and application of a decision support system. Resources, Conservation \& Recycling, 37(4), 301-328. https://doi.org/10.1016/S0921-3449(02)00076-9

Gabbar, H. A., Aboughaly, M., \& Ayoub, N. (2018). Comparative study of MSW heat treatment processes and electricity generation. Journal of the Energy Institute, 91(4), 481-488. https://doi.org/10.1016/j. joei.2017.04.009

Gadaleta, G., De Gisi, S., Binetti, S. M., \& Notarnicola, M. (2020). Outlining a comprehensive techno-economic approach to evaluate the performance of an advanced sorting plant for plastic waste recovery. Process Safety and Environmental Protection, 142, 248-261. https://doi.org/10.1016/j.psep.2020.07. 008

Gala, A., Guerrero, M., \& Serra, J. M. (2020). Characterization of post-consumer plastic film waste from mixed MSW in Spain: A key point for the successful implementation of sustainable plastic waste management strategies. Waste Management, 111, 22-33. https://doi.org/10.1016/j.wasman.2020.05. 019

Getahun, T., Mengistie, E., Haddis, A., Wasie, F., Alemayehu, E., Dadi, D., Van Gerven, T., \& Van der Bruggen, B. (2012). Municipal solid waste generation in growing urban areas in Africa: Current practices and relation to socioeconomic factors in Jimma Ethiopia. Environmental Monitoring and Assessment, 184(10), 6337-6345. https://doi.org/10.1007/s10661-011-2423-x

Ghiani, G., Laganà, D., Manni, E., Musmanno, R., \& Vigo, D. (2014). Operations research in solid waste management: A survey of strategic and tactical issues. Computers \& Operations Research, 44, $22-32$. https://doi.org/10.1016/j.cor.2013.10.006

Ghiani, G., Manni, A., Manni, E., \& Moretto, V. (2021). Optimizing a waste collection system with solid waste transfer stations. Computers and Industrial Engineering. https://doi.org/10.1016/j.cie.2021. 107618 
Gikas, P., Zhu, B., Batistatos, N. I., \& Zhang, R. (2018). Evaluation of the rotary drum reactor process as pretreatment technology of municipal solid waste for thermophilic anaerobic digestion and biogas production. Journal of Environmental Management, 216, 96-104. https://doi.org/10.1016/j.jenvman. 2017.07.050

Goes, G., Bandeira, R., Gonçalves, D., de Almeida D’Agosto, M., \& Oliveira, C. (2020). The effect of ecodriving initiatives toward sustainable urban waste collection. International Journal of Sustainable Transportation, 14(8), 569-578. https://doi.org/10.1080/15568318.2019.1584933

Golwala, H., Zhang, X., Iskander, S. M., \& Smith, A. L. (2021). Solid waste: An overlooked source of microplastics to the environment. Science of the Total Environment. https://doi.org/10.1016/j.scito tenv.2020.144581

Greco, G., Allegrini, M., Del Lungo, C., Savellini, P. G., \& Gabellini, L. (2015). Drivers of solid waste collection costs. Empirical evidence from Italy. Journal of Cleaner Production, 106, 364-371. https:// doi.org/10.1016/j.jclepro.2014.07.011

Gu, B., Jiang, S., Wang, H., Wang, Z., Jia, R., Yang, J., He, S., \& Cheng, R. (2017). Characterization, quantification and management of China's municipal solid waste in spatiotemporal distributions: A review. Waste Management, 61, 67-77. https://doi.org/10.1016/j.wasman.2016.11.039

Gu, B., Wang, H., Chen, Z., Jiang, S., Zhu, W., Liu, M., Chen, Y., Wu, Y., He, S., \& Cheng, R. J. (2015). Characterization, quantification and management of household solid waste: A case study in China. Resources, Conservation \& Recycling, 98, 67-75. https://doi.org/10.1016/j.resconrec.2015.03.001

Gu, F., Zhang, W., Guo, J., \& Hall, P. (2019). Exploring "Internet+ Recycling": Mass balance and life cycle assessment of a waste management system associated with a mobile application. Science of the Total Environment, 649, 172-185. https://doi.org/10.1016/j.scitotenv.2018.08.298

Gu, J., Pei, W., Tang, S., Yan, F., Peng, Z., Huang, C., Yang, J., \& Yong, Q. (2020). Procuring biologically active galactomannans from spent coffee ground (SCG) by autohydrolysis and enzymatic hydrolysis. International Journal of Biological Macromolecules, 149, 572-580. https://doi.org/10.1016/j.ijbio mac.2020.01.281

Gui, S., Zhao, L., \& Zhang, Z. (2019). Does municipal solid waste generation in China support the Environmental Kuznets Curve? New evidence from spatial linkage analysis. Waste Management, 84, 310319. https://doi.org/10.1016/j.wasman.2018.12.006

Gundupalli, S. P., Hait, S., \& Thakur, A. (2017). A review on automated sorting of source-separated municipal solid waste for recycling. Waste Management, 60, 56-74. https://doi.org/10.1016/j.wasman.2016. 09.015

Guo, B., Geng, Y., Sterr, T., Zhu, Q., \& Liu, Y. (2017). Investigating public awareness on circular economy in western China: A case of Urumqi Midong. Journal of Cleaner Production, 142, 2177-2186. https://doi.org/10.1016/j.jclepro.2016.11.063

Hannan, M., Begum, R., Al-Shetwi, A. Q., Ker, P., Al Mamun, M., Hussain, A., Basri, H., \& Mahlia, T. (2020). Waste collection route optimisation model for linking cost saving and emission reduction to achieve sustainable development goals. Sustainable Cities and Society, 62, 102393. https://doi.org/10. 1016/j.scs.2020.102393

Hansen, T. L., la Cour Jansen, J., Davidsson, А̊., \& Christensen, T. H. (2007). Effects of pre-treatment technologies on quantity and quality of source-sorted municipal organic waste for biogas recovery. Waste Management, 27(3), 398-405. https://doi.org/10.1016/j.wasman.2006.02.014

Hasan, M., Rasul, M., Khan, M., Ashwath, N., \& Jahirul, M. (2021). Energy recovery from municipal solid waste using pyrolysis technology: A review on current status and developments. Renewable and Sustainable Energy Reviews, 145, 111073. https://doi.org/10.1016/j.rser.2021.111073

Hassan, G. K., Hemdan, B. A., \& El-Gohary, F. A. (2020). Utilization of food waste for bio-hydrogen and bio-methane production: Influences of temperature, OLR, and in situ aeration. Journal of Material Cycles and Waste Management, 22, 1218-1226. https://doi.org/10.1007/s10163-020-01014-5

Heidari, R., Yazdanparast, R., \& Jabbarzadeh, A. (2019). Sustainable design of a municipal solid waste management system considering waste separators: A real-world application. Sustainable Cities and Society, 47, 101457. https://doi.org/10.1016/j.scs.2019.101457

Hoque, M. M., \& Rahman, M. T. U. (2020). Landfill area estimation based on solid waste collection prediction using ANN model and final waste disposal options. Journal of Cleaner Production, 256, 120387. https://doi.org/10.1016/j.jclepro.2020.120387

Hou, J., Jin, Y., \& Chen, F. (2020). Should waste separation be mandatory? A study on public's response to the policies in China. International Journal of Environmental Research Public Health, 17(12), 4539. https://doi.org/10.3390/ijerph17124539

Kammen, D. M., \& Sunter, D. A. (2016). City-integrated renewable energy for urban sustainability. Science, 352(6288), 922-928. https://doi.org/10.1126/science.aad9302 
Kan, T., Strezov, V., \& Evans, T. J. (2016). Lignocellulosic biomass pyrolysis: A review of product properties and effects of pyrolysis parameters. Renewable and Sustainable Energy Reviews, 57, 1126-1140. https://doi.org/10.1016/j.rser.2015.12.185

Kannah, R. Y., Merrylin, J., Devi, T. P., Kavitha, S., Sivashanmugham, P., Kumar, G., \& Banu, J. R. (2020). Food waste valorization: Biofuels and value added product recovery. Bioresource Technology Reports, 11, 100524. https://doi.org/10.1016/j.biteb.2020.100524

Karthikeyan, O., Balasubramanian, R., \& Wong, J. (2017) Current Developments in Biotechnology and Bioengineering, pp. 135-156, Elsevier.

Kavitha, S., Banu, J. R., Priya, A. A., \& Yeom, I. T. (2017). Liquefaction of food waste and its impacts on anaerobic biodegradability, energy ratio and economic feasibility. Applied Energy, 208, 228-238. https://doi.org/10.1016/j.apenergy.2017.10.049

Kaza, S., Yao, L., Bhada-Tata, P., \& Van Woerden, F. (2018) What a waste 2.0: a global snapshot of solid waste management to 2050, The World Bank.

Klemeš, J. J., Van Fan, Y., Tan, R. R., \& Jiang, P. (2020). Minimising the present and future plastic waste, energy and environmental footprints related to COVID-19. Renewable and Sustainable Energy Reviews, 127, 109883. https://doi.org/10.1016/j.rser.2020.109883

Knickmeyer, D. (2020). Social factors influencing household waste separation: A literature review on good practices to improve the recycling performance of urban areas. Journal of Cleaner Production, 245, 118605. https://doi.org/10.1016/j.jclepro.2019.118605

Ko, S., Kim, W., Shin, S.-C., \& Shin, J. (2020). The economic value of sustainable recycling and waste management policies: The case of a waste management crisis in South Korea. Waste Management, 104, 220-227. https://doi.org/10.1016/j.wasman.2020.01.020

Kong, X., Xu, S., Liu, J., Li, H., Zhao, K., \& He, L. (2016). Enhancing anaerobic digestion of highpressure extruded food waste by inoculum optimization. Journal of Environmental Management, 166, 31-37. https://doi.org/10.1016/j.jenvman.2015.10.002

Krishnan, S., Din, M. F. M., Taib, S. M., Ling, Y. E., Puteh, H., Mishra, P., Nasrullah, M., Sakinah, M., Wahid, Z. A., \& Rana, S. (2019). Process constraints in sustainable bio-hythane production from wastewater: Technical note. Bioresource Technology Reports, 5, 359-363. https://doi.org/10. 1016/j.biteb.2018.05.003

Kumar, M.I., Naveen, S., \& Ramalakshmi, A. (2021) Sustainable Bioeconomy, pp. 85-100, Springer.

Kumar, A., \& Samadder, S. R. (2017). A review on technological options of waste to energy for effective management of municipal solid waste. Waste Management, 69, 407-422. https://doi.org/10.1016/j. wasman.2017.08.046

Kurniawan, T. A., Lo, W., Singh, D., Othman, M. H. D., Avtar, R., Hwang, G. H., Albadarin, A. B., Kern, A. O., \& Shirazian, S. (2021). A societal transition of MSW management in Xiamen (China) toward a circular economy through integrated waste recycling and technological digitization. Environmental Pollution, 277, 116741. https://doi.org/10.1016/j.envpol.2021.116741

Lebreton, L., \& Andrady, A. (2019). Future scenarios of global plastic waste generation and disposal. Palgrave Communications, 5(1), 1-11. https://doi.org/10.1057/s41599-018-0212-7

Lee, D.-J., Lu, J.-S., \& Chang, J.-S. (2020). Pyrolysis synergy of municipal solid waste (MSW): A review. Bioresource Technology. https://doi.org/10.1016/j.biortech.2020.123912

Lella, J., Mandla, V. R., \& Zhu, X. (2017). Solid waste collection/transport optimization and vegetation land cover estimation using Geographic Information System (GIS): A case study of a proposed smart-city. Sustainable Cities and Society, 35, 336-349. https://doi.org/10.1016/j.scs.2017.08.023

Li, L., Wang, Q., Bi, W., Hou, J., Xue, Y., Mao, D., Das, R., Luo, Y., \& Li, X. (2020a). Municipal solid waste treatment system increases ambient airborne bacteria and antibiotic resistance genes. Environmental Science \& Technology, 54(7), 3900-3908. https://doi.org/10.1021/acs.est.9b07641

Li, X., Bi, F., Han, Z., Qin, Y., Wang, H., \& Wu, W. (2019). Garbage source classification performance, impact factor, and management strategy in rural areas of China: A case study in Hangzhou. Waste Management, 89, 313-321. https://doi.org/10.1016/j.wasman.2019.04.020

Li, Y., Jin, Y., Li, J., Li, H., Yu, Z., \& Nie, Y. (2017). Effects of thermal pretreatment on degradation kinetics of organics during kitchen waste anaerobic digestion. Energy, 118, 377-386. https://doi. org/10.1016/j.energy.2016.12.041

Li, Z., Wang, Q., Zhang, T., Wang, H., \& Chen, T. (2020b). A novel bulk density-based recognition method for kitchen and dry waste: A case study in Beijing, China. Waste Management, 114, 89-95. https://doi.org/10.1016/j.wasman.2020.07.005

Liang, J., Yu, Z., Chen, L., Fang, S., \& Ma, X. (2019). Microwave pretreatment power and duration time effects on the catalytic pyrolysis behaviors and kinetics of water hyacinth. Bioresource Technology, 286, 121369. https://doi.org/10.1016/j.biortech.2019.121369 
Liu, C., \& Wu, X.-W. (2011). Factors influencing municipal solid waste generation in China: A multiple statistical analysis study. Waste Management \& Research, 29(4), 371-378. https://doi.org/10.1177/ $0734242 X 10380114$

Liu, H., Wang, C., Zhang, J., Zhao, W., \& Fan, M. (2020). Pyrolysis kinetics and thermodynamics of typical plastic waste. Energy \& Fuels, 34(2), 2385-2390. https://doi.org/10.1021/acs.energyfuels. 9b04152

Lombardi, L., Carnevale, E., \& Corti, A. (2015). A review of technologies and performances of thermal treatment systems for energy recovery from waste. Waste Management, 37, 26-44. https://doi.org/ 10.1016/j.wasman.2014.11.010

Lou, C. X., Shuai, J., Luo, L., \& Li, H. (2020). Optimal transportation planning of classified domestic garbage based on map distance. Journal of Environmental Management, 254, 109781. https://doi. org/10.1016/j.jenvman.2019.109781

Lu, H., \& Sidortsov, R. (2019). Sorting out a problem: A co-production approach to household waste management in Shanghai, China. Waste Management, 95, 271-277. https://doi.org/10.1016/j.wasman.2019.06.020

Lu, J.-S., Chang, Y., Poon, C.-S., \& Lee, D.-J. (2020). Slow pyrolysis of municipal solid waste (MSW): A review. Bioresource Technology, 312, 123615. https://doi.org/10.1016/j.biortech.2020.123615

Lu, J.-W., Zhang, S., Hai, J., \& Lei, M. (2017). Status and perspectives of municipal solid waste incineration in China: A comparison with developed regions. Waste Management, 69, 170-186. https:// doi.org/10.1016/j.wasman.2017.04.014

Lv, J., Dong, H., Geng, Y., \& Li, H. (2020). Optimization of recyclable MSW recycling network: A Chinese case of Shanghai. Waste Management, 102, 763-772. https://doi.org/10.1016/j.wasman.2019.11.041

Malav, L. C., Yadav, K. K., Gupta, N., Kumar, S., Sharma, G. K., Krishnan, S., Rezania, S., Kamyab, H., Pham, Q. B., \& Yadav, S. (2020). A review on municipal solid waste as a renewable source for wasteto-energy project in India: Current practices, challenges, and future opportunities. Journal of Cleaner Production, 277, 123227. https://doi.org/10.1016/j.jclepro.2020.123227

Malinauskaite, J., Jouhara, H., Czajczyńska, D., Stanchev, P., Katsou, E., Rostkowski, P., Thorne, R. J., Colon, J., Ponsá, S., \& Al-Mansour, F. (2017). Municipal solid waste management and waste-toenergy in the context of a circular economy and energy recycling in Europe. Energy, 141, 2013-2044. https://doi.org/10.1016/j.energy.2017.11.128

Matsumoto, S. (2011). Waste separation at home: Are Japanese municipal curbside recycling policies efficient? Resources, Conservation \& Recycling, 55(3), 325-334. https://doi.org/10.1016/j.resconrec. 2010.10.005

Melikoglu, M. (2020). Reutilisation of food wastes for generating fuels and value added products: A global review. Environmental Technology \& Innovation, 19, 101040. https://doi.org/10.1016/j.eti.2020. 101040

Men, J., Jiang, P., \& Xu, H. (2019). A chance constrained programming approach for HazMat capacitated vehicle routing problem in Type-2 fuzzy environment. Journal of Cleaner Production, 237, 117754. https://doi.org/10.1016/j.jclepro.2019.117754

Miafodzyeva, S., \& Brandt, N. (2013). Recycling behaviour among householders: Synthesizing determinants via a meta-analysis. Waste and Biomass Valorization, 4(2), 221-235. https://doi.org/10.1007/ s12649-01

Mmereki, D., Baldwin, A., \& Li, B. (2016). A comparative analysis of solid waste management in developed, developing and lesser developed countries. Environmental Technology Reviews, 5(1), 120-141. https://doi.org/10.1080/21622515.2016.1259357

Moh, Y. (2017). Solid waste management transformation and future challenges of source separation and recycling practice in Malaysia. Resources, Conservation \& Recycling, 116, 1-14. https://doi.org/10. 1016/j.resconrec.2016.09.012

Mohammadi, M., Jämsä-Jounela, S.-L., \& Harjunkoski, I. (2019). Optimal planning of municipal solid waste management systems in an integrated supply chain network. Computers \& Chemical Engineering, 123, 155-169. https://doi.org/10.1016/j.compchemeng.2018.12.022

Mohsenizadeh, M., Tural, M. K., \& Kentel, E. (2020). Municipal solid waste management with cost minimization and emission control objectives: A case study of Ankara. Sustainable Cities and Society, 52, 101807. https://doi.org/10.1016/j.scs.2019.101807

Monzambe, G. M., Mpofu, K., \& Daniyan, I. A. (2021). Optimal location of landfills and transfer stations for municipal solid waste in developing countries using non-linear programming. Sustainable Futures, 3, 100046. https://doi.org/10.1016/j.sftr.2021.100046

Mukherjee, C., Denney, J., Mbonimpa, E., Slagley, J., \& Bhowmik, R. (2020). A review on municipal solid waste-to-energy trends in the USA. Renewable and Sustainable Energy Reviews, 119, 109512. https:// doi.org/10.1016/j.rser.2019.109512 
Müssig, S., Fidler, F., Haddad, D., Hiller, K. H., Wintzheimer, S., \& Mandel, K. (2019). Supraparticles with a Magnetic Fingerprint Readable by Magnetic Particle Spectroscopy: An Alternative beyond Optical Tracers. Advanced Materials Technologies, 4(9), 1900300. https://doi.org/10.1002/admt.201900300

Nasiri, M.M., Heidari, R., Yazdanparast, R., \& Akbarian, N. (2017) Robust Possibilistic Programming Approach for the Design of Tehran Municipal Solid Waste Management System. 13th International Conference on Industrial Engineering (IIEC 2017), Mazandaran, Iran. 2017.

Nguyen-Trong, K., Nguyen-Thi-Ngoc, A., Nguyen-Ngoc, D., \& Dinh-Thi-Hai, V. (2017). Optimization of municipal solid waste transportation by integrating GIS analysis, equation-based, and agent-based model. Waste Management, 59, 14-22. https://doi.org/10.1016/j.wasman.2016.10.048

Nie, Y., Wu, Y., Zhao, J., Zhao, J., Chen, X., Maraseni, T., \& Qian, G.J.W.m. (2018). Is the finer the better for municipal solid waste (MSW) classification in view of recyclable constituents? A comprehensive social, economic and environmental analysis. Waste Management, 79, 472-480. https://doi.org/10. 1016/j.wasman.2018.08.016

Nowakowski, P., Szwarc, K., \& Boryczka, U. (2020). Combining an artificial intelligence algorithm and a novel vehicle for sustainable e-waste collection. Science of the Total Environment, 730, 138726. https://doi.org/10.1016/j.scitotenv.2020.138726

O’Toole, M., \& Peyton, A. (2019) Classification of Non-ferrous Scrap Metal using Two Component Magnetic Induction Spectroscopy, pp. 1-6, IEEE.

Okonta, F., Ngcobo, N., Mtsweni, M., \& Harris, D. (2017) Compaction Properties of Municipal Solid Waste, pp. 279-292, Springer.

Ooi, J. K., Woon, K. S., \& Hashim, H. (2021). A multi-objective model to optimize country-scale municipal solid waste management with economic and environmental objectives: A case study in Malaysia. Journal of Cleaner Production, 316, 128366. https://doi.org/10.1016/j.jclepro.2021. 128366

Oribe-Garcia, I., Kamara-Esteban, O., Martin, C., Macarulla-Arenaza, A. M., \& Alonso-Vicario, A. (2015). Identification of influencing municipal characteristics regarding household waste generation and their forecasting ability in Biscay. Waste Management, 39, 26-34. https://doi.org/10. 1016/j.wasman.2015.02.017

Owusu, P. K. (2020). Smart garbage monitoring system using internet of things. Middle East Journal of Applied Science \& Technology, 3(2), 74-82.

Owusu, V., Adjei-Addo, E., \& Sundberg, C. (2013). Do economic incentives affect attitudes to solid waste source separation? Evidence from Ghana. Resources, Conservation \& Recycling, 78, 115123. https://doi.org/10.1016/j.resconrec.2013.07.002

Panigrahi, S., \& Dubey, B. K. (2019). A critical review on operating parameters and strategies to improve the biogas yield from anaerobic digestion of organic fraction of municipal solid waste. Renewable Energy, 143, 779-797. https://doi.org/10.1016/j.renene.2019.05.040

Papageorgiou, A., Karagiannidis, A., Barton, J. R., \& Kalogirou, E. (2009). Municipal solid waste management scenarios for Attica and their greenhouse gas emission impact. Waste Management \& Research, 27(9), 928-937. https://doi.org/10.1177/0734242X09350787

Patsalou, M., Menikea, K. K., Makri, E., Vasquez, M. I., Drouza, C., \& Koutinas, M. (2017). Development of a citrus peel-based biorefinery strategy for the production of succinic acid. Journal of Cleaner Production, 166, 706-716. https://doi.org/10.1016/j.jclepro.2017.08.039

Pellegrinelli, S. (2019). Configuration and reconfiguration of robotic systems for waste macro sorting. The International Journal of Advanced Manufacturing Technology, 102(9-12), 3677-3687. https://doi.org/10.1007/s00170-019-03289-x

Peri, G., Ferrante, P., La Gennusa, M., Pianello, C., \& Rizzo, G. (2018). Greening MSW management systems by saving footprint: The contribution of the waste transportation. Journal of Environmental Management, 219, 74-83. https://doi.org/10.1016/j.jenvman.2018.04.098

Pluskal, J., Šomplák, R., Nevrlý, V., Smejkalová, V., \& Pavlas, M. (2020). Strategic Decisions Leading to Sustainable Waste Management: Separation, Sorting and Recycling Possibilities. Journal of Cleaner Production, 278, 123359. https://doi.org/10.1016/j.jclepro.2020.123359

Qiao, Q., Tao, F., Wu, H., Yu, X., \& Zhang, M. (2020). Optimization of a Capacitated Vehicle Routing Problem for Sustainable Municipal Solid Waste Collection Management Using the PSO-TS Algorithm. International Journal of Environmental Research Public Health, 17(6), 2163. https://doi. org/10.3390/ijerph17062163

Qiu, L., Deng, Y., Wang, F., Davaritouchaee, M., \& Yao, Y. (2019). A review on biochar-mediated anaerobic digestion with enhanced methane recovery. Renewable and Sustainable Energy Reviews, 115, 109373. https://doi.org/10.1016/j.rser.2019.109373 
Qureshi, U., Imtiaz, B., \& Jamal, Y. (2020). Synthesizing PET and food waste into refuse plastic fuel (RPF): Optimization and kinetic modeling. Journal of Thermal Analysis and Calorimetry, 140(4), 1745-1758. https://doi.org/10.1007/s10973-019-08934-X

Ragaert, K., Delva, L., \& Van Geem, K. (2017). Mechanical and chemical recycling of solid plastic waste. Waste Management, 69, 24-58. https://doi.org/10.1016/j.wasman.2017.07.044

Rajasekhar, M., Rao, N. V., Rao, G. C., Priyadarshini, G., \& Kumar, N. J. (2015). Energy generation from municipal solid waste by innovative technologies-plasma gasification. Procedia Materials Science, 10, 513-518. https://doi.org/10.1016/j.mspro.2015.06.094

Rani, M., Marchesi, C., Federici, S., Rovelli, G., Alessandri, I., Vassalini, I., Ducoli, S., Borgese, L., Zacco, A., \& Bilo, F. (2019). Miniaturized Near-Infrared (MicroNIR) Spectrometer in Plastic Waste Sorting. Materials, 12(17), 2740.

Rathore, P., \& Sarmah, S. (2019). Modeling transfer station locations considering source separation of solid waste in urban centers: A case study of Bilaspur city, India. Journal of Cleaner Production, $211,44-60$.

Rathore, P., Sarmah, S. P., \& Singh, A. (2020). Location-allocation of bins in urban solid waste management: A case study of Bilaspur city, India. Environment, Development and Sustainability, 22(4), 3309-3331. https://doi.org/10.1007/s10668-019-00347-y

Razali, F., Daud, D., Wai, C. W., \& Jiram, W. R. A. (2020). Waste separation at source behaviour among Malaysian households: The Theory of Planned Behaviour with moral norm. Journal of Cleaner Production, 271, 122025. https://doi.org/10.3390/ma12172740

Rodrigues, S., Martinho, G., \& Pires, A. (2016). Waste collection systems. Part A: A taxonomy. Journal of Cleaner Production, 113, 374-387. https://doi.org/10.1016/j.jclepro.2015.09.143

Salah, M.M., Al-Khatib, I.A., \& Kontogianni, S. (2020). Contemporary Environmental Issues and Challenges in Era of Climate Change, pp. 245-260, Springer.

Sánchez-Arias, M., Riojas-Rodríguez, H., Catalán-Vázquez, M., Terrazas-Meraz, M., Rosas, I., EspinosaGarcía, A., Santos-Luna, R., \& Siebe, C. (2019). Socio-environmental assessment of a landfill using a mixed study design: A case study from México. Waste Management, 85, 42-59. https://doi.org/10. 1016/j.wasman.2018.12.012

Schulze, S., Nikrityuk, P., Abosteif, Z., Guhl, S., Richter, A., \& Meyer, B. (2017). Heat and mass transfer within thermogravimetric analyser: From simulation to improved estimation of kinetic data for char gasification. Fuel, 187, 338-348. https://doi.org/10.1016/j.fuel.2016.09.048

Sebastian, R. M., Kumar, D., \& Alappat, B. J. (2020). Demonstration of estimation of incinerability of municipal solid waste using incinerability index. Environment, Development and Sustainability, 22(5), 4821-4844. https://doi.org/10.1007/s10668-019-00407-3

Shah, A. V., Srivastava, V. K., Mohanty, S. S., \& Varjani, S. (2021). Municipal solid waste as a sustainable resource for energy production: State-of-the-art review. Journal of Environmental Chemical Engineering. https://doi.org/10.1016/j.jece.2021.105717

Shahab, R. L., Brethauer, S., Davey, M. P., Smith, A. G., Vignolini, S., Luterbacher, J. S., \& Studer, M. H. (2020). A heterogeneous microbial consortium producing short-chain fatty acids from lignocellulose. Science. https://doi.org/10.1126/science.abb1214

Shen, M., Song, B., Zeng, G., Zhang, Y., Huang, W., Wen, X., \& Tang, W. (2020). Are biodegradable plastics a promising solution to solve the global plastic pollution? Environmental Pollution, 263, 114469. https://doi.org/10.1016/j.envpol.2020.114469

Shi, Y., Wang, Y., Yue, Y., Zhao, J., Maraseni, T., \& Qian, G. (2021). Unbalanced status and multidimensional influences of municipal solid waste management in Africa. Chemosphere, 281, 130884. https:// doi.org/10.1016/j.chemosphere.2021.130884

Signoret, C., Caro-Bretelle, A.-S., Lopez-Cuesta, J.-M., Ienny, P., \& Perrin, D. (2019). MIR spectral characterization of plastic to enable discrimination in an industrial recycling context: II Specific Case of Polyolefins. Waste Management, 98, 160-172. https://doi.org/10.1016/j.wasman.2019.08.010

Signoret, C., Caro-Bretelle, A.-S., Lopez-Cuesta, J.-M., Ienny, P., \& Perrin, D. (2020). Alterations of plastics spectra in MIR and the potential impacts on identification towards recycling. Resources, Conservation \& Recycling, 161, 104980. https://doi.org/10.1016/j.resconrec.2020.104980

Sindhu, R., Gnansounou, E., Rebello, S., Binod, P., Varjani, S., Thakur, I. S., Nair, R. B., \& Pandey, A. (2019). Conversion of food and kitchen waste to value-added products. Journal of Environmental Management, 241, 619-630. https://doi.org/10.1016/j.jenvman.2019.02.053

Singh, S., \& Behera, S.N. (2019). Development of GIS-Based Optimization Method for Selection of Transportation Routes in Municipal Solid Waste Management, pp. 319-331, Springer.

Sipra, A. T., Gao, N., \& Sarwar, H. (2018). Municipal solid waste (MSW) pyrolysis for bio-fuel production: A review of effects of MSW components and catalysts. Fuel Processing Technology, 175, 131-147. https://doi.org/10.1016/j.fuproc.2018.02.012 
Slavík, J., Dolejš, M., \& Rybová, K. (2021). Mixed-method approach incorporating Geographic information system (GIS) tools for optimizing collection costs and convenience of the biowaste separate collection. Waste Management, 134, 177-186. https://doi.org/10.1016/j.wasman.2021.07.018

Soto, J., Martín-Lara, M., Blázquez, G., Godoy, V., Quesada, L., \& Calero, M. (2020). Novel pre-treatment of dirty post-consumer polyethylene film for its mechanical recycling. Process Safety and Environmental Protection, 139, 315-324. https://doi.org/10.1016/j.psep.2020.04.044

Stoeva, K., \& Alriksson, S. (2017). Influence of recycling programmes on waste separation behaviour. Waste Management, 68, 732-741. https://doi.org/10.1016/j.wasman.2017.06.005

Tai, J., Zhang, W., Che, Y., \& Feng, D. (2011). Municipal solid waste source-separated collection in China: A comparative analysis. Waste Management, 31(8), 1673-1682. https://doi.org/10.1016/j.wasman. 2011.03.014

Takahashi, W. (2020). Economic rationalism or administrative rationalism? Curbside collection systems in Sweden and Japan. Journal of Cleaner Production, 242, 118288. https://doi.org/10.1016/j.jclepro. 2019.118288

Tang, Y., Huang, Q., Sun, K., Chi, Y., \& Yan, J. (2018). Co-pyrolysis characteristics and kinetic analysis of organic food waste and plastic. Bioresource Technology, 249, 16-23. https://doi.org/10.1016/j.biort ech.2017.09.210

Taşkin, A., \& Demir, N. (2020). Life cycle environmental and energy impact assessment of sustainable urban municipal solid waste collection and transportation strategies. Sustainable Cities and Society, 61, 102339. https://doi.org/10.1016/j.scs.2020.102339

Teerioja, N., Moliis, K., Kuvaja, E., Ollikainen, M., Punkkinen, H., \& Merta, E. (2012). Pneumatic vs door-to-door waste collection systems in existing urban areas: a comparison of economic performance. Waste Management, 32(10), 1782-1791. https://doi.org/10.1016/j.wasman.2012.05.027

Thomas, P., \& Soren, N. (2020). An overview of municipal solid waste-to-energy application in Indian scenario. Environment, Development and Sustainability, 22(2), 575-592. https://doi.org/10.1007/ s10668-018-0235-7

Tian, X., Zhang, X., Zhou, Y., \& Yu, X. (2016). Regional income inequality in China revisited: A perspective from club convergence. Economic Modelling, 56, 50-58. https://doi.org/10.1016/j.econm od.2016.02.028

Tirkolaee, E. B., Alinaghian, M., Hosseinabadi, A. A. R., Sasi, M. B., \& Sangaiah, A. K. (2019). An improved ant colony optimization for the multi-trip Capacitated Arc Routing Problem. Computers \& Electrical Engineering, 77, 457-470. https://doi.org/10.1016/j.compeleceng.2018.01.040

Tirkolaee, E. B., Mahdavi, I., Esfahani, M. M. S., \& Weber, G.-W. (2020). A robust green location-allocation-inventory problem to design an urban waste management system under uncertainty. Waste Management, 102, 340-350. https://doi.org/10.1016/j.wasman.2019.10.038

Tong, Y., Liu, J., \& Liu, S. (2020). China is implementing "Garbage Classification" action. Environmental Pollution, 259, 113707. https://doi.org/10.1016/j.envpol.2019.113707

Torkashvand, J., Emamjomeh, M. M., Gholami, M., \& Farzadkia, M. (2021). Analysis of cost-benefit in life-cycle of plastic solid waste: Combining waste flow analysis and life cycle cost as a decision support tool to the selection of optimum scenario. Environment, Development and Sustainability. https://doi.org/10.1007/s10668-020-01208-9

Varotto, A., \& Spagnolli, A. (2017). Psychological strategies to promote household recycling. A systematic review with meta-analysis of validated field interventions. Journal of Environmental Psychology, 51, 168-188. https://doi.org/10.1016/j.jenvp.2017.03.011

Vasileva, E., \& Ivanova, D. (2014). Towards a sustainable consumer model: The case study of B ulgarian recyclers. International Journal of Consumer Studies, 38(5), 475-484. https://doi.org/10.1111/ ijcs. 12123

Vazquez, Y. V., Barragán, F., Castillo, L. A., \& Barbosa, S. E. (2020). Analysis of the relationship between the amount and type of MSW and population socioeconomic level: Bahía Blanca case study Argentina. Heliyon, 6(6), e04343. https://doi.org/10.1016/j.heliyon.2020.e04343

Veluchamy, C., \& Kalamdhad, A. S. (2017). Enhanced methane production and its kinetics model of thermally pretreated lignocellulose waste material. Bioresource Technology, 241, 1-9. https://doi. org/10.1016/j.biortech.2017.05.068

VIC Government, (2021). Standardising household recycling across Victoria. Retrieved September 12, 2021, from https://www.vic.gov.au/Standardising-household-recycling-across-Victoria

Viotti, P., Polettini, A., Pomi, R., \& Innocenti, C. (2003). Genetic algorithms as a promising tool for optimisation of the MSW collection routes. Waste Management \& Research, 21(4), 292-298. https://doi.org/10.1177/0734242X0302100402 
Vu, H. L., Bolingbroke, D., Ng, K. T. W., \& Fallah, B. (2019a). Assessment of waste characteristics and their impact on GIS vehicle collection route optimization using ANN waste forecasts. Waste Management, 88, 118-130. https://doi.org/10.1016/j.wasman.2019.03.037

Vu, H. L., Ng, K. T. W., \& Bolingbroke, D. (2019b). Time-lagged effects of weekly climatic and socioeconomic factors on ANN municipal yard waste prediction models. Waste Management, 84, 129140. https://doi.org/10.1016/j.wasman.2018.11.038

Wagland, S.T. (2019) Substitute Natural Gas from Waste, pp. 37-48, Elsevier.

Wang, K., \& Nai, W. (2021) Application of 5G Wireless Communication Technology in Hazardous Medical Waste Treatment, pp. 87-90, IEEE.

Wang, B., Farooque, M., Zhong, R. Y., Zhang, A., \& Liu, Y. (2021a). Internet of Things (IoT)-Enabled accountability in source separation of household waste for a circular economy in China. Journal of Cleaner Production, 300, 126773. https://doi.org/10.1016/j.jclepro.2021.126773

Wang, F., Wang, P., Raheem, A., Ji, G., Memon, M. Z., Song, Y., \& Zhao, M. (2019a). Enhancing hydrogen production from biomass pyrolysis by dental-wastes-derived sodium zirconate. International Journal of Hydrogen Energy, 44(43), 23846-23855. https://doi.org/10.1016/j.ijhydene.2019.07.095

Wang, H., \& Wang, C. (2013). Municipal solid waste management in Beijing: Characteristics and challenges. Waste Management \& Research, 31(1), 67-72. https://doi.org/10.1177/0734242X12468199

Wang, Q., Long, X., Li, L., Kong, L., Zhu, X., \& Liang, H. (2020). Engagement factors for waste sorting in China: The mediating effect of satisfaction. Journal of Cleaner Production, 267, 122046. https://doi.org/10.1016/j.jclepro.2020.122046

Wang, W., Themelis, N. J., Sun, K., Bourtsalas, A. C., Huang, Q., Zhang, Y., \& Wu, Z. (2019b). Current influence of China's ban on plastic waste imports. Waste Disposal \& Sustainable Energy, 1(1), 67-78. https://doi.org/10.1007/s42768-019-00005-Z

Wang, Y., Shi, Y., Zhou, J., Zhao, J., Maraseni, T., \& Qian, G. (2021b). Implementation effect of municipal solid waste mandatory sorting policy in Shanghai. Journal of Environmental Management, 298, 113512. https://doi.org/10.1016/j.jenvman.2021.113512

Wannapokin, A., Cheng, Y.-T., Wu, S.-Z., Hsieh, P.-H., \& Hung, C.-H. (2020). Potential of bio-hydrogen production by $\mathrm{C}$. pasteurianum co-immobilized with selected nano-metal particles. International Journal of Hydrogen Energy, 46(20), 11337-11344. https://doi.org/10.1016/j.ijhydene.2020.05.238

Woon, K. S., \& Lo, I. M. (2016). A proposed framework of food waste collection and recycling for renewable biogas fuel production in Hong Kong. Waste Management, 47, 3-10. https://doi.org/10.1016/j. wasman.2015.03.022

Wu, Z., Zhang, Y., Chen, Q., \& Wang, H. (2021). Attitude of Chinese public towards municipal solid waste sorting policy: A text mining study. Science of the Total Environment, 756, 142674. https://doi.org/10. 1016/j.scitotenv.2020.142674

Xiao, S., Dong, H., Geng, Y., \& Brander, M. (2018). An overview of China's recyclable waste recycling and recommendations for integrated solutions. Resources, Conservation \& Recycling, 134, 112-120. https://doi.org/10.1016/j.resconrec.2018.02.032

Xiao, S., Dong, H., Geng, Y., Francisco, M.-J., Pan, H., \& Wu, F. (2020a). An overview of the municipal solid waste management modes and innovations in Shanghai, China. Environmental Science and Pollution Research International, 27(24), 29943-29953. https://doi.org/10.1007/s11356-020-09398-5

Xiao, S., Dong, H., Geng, Y., Tian, X., Liu, C., \& Li, H. (2020b). Policy impacts on Municipal Solid Waste management in Shanghai: A system dynamics model analysis. Journal of Cleaner Production, 262, 121366. https://doi.org/10.1016/j.jclepro.2020.121366

Xiao, Y., \& Zhou, B. (2020). Does the development of delivery industry increase the production of municipal solid waste?-An empirical study of China. Resources, Conservation \& Recycling, 155, 104577. https://doi.org/10.1016/j.resconrec.2019.104577

Xin, C.-L., Liang, S., \& Shen, F.-W. (2020). Reconfiguration of garbage collection system based on Voronoi graph theory: A simulation case of Beijing region. Journal of Combinatorial Optimization. https:// doi.org/10.1007/s10878-020-00614-Z

Xiong, X., Iris, K., Tsang, D. C., Bolan, N. S., Ok, Y. S., Igalavithana, A. D., Kirkham, M., Kim, K.-H., \& Vikrant, K. (2019). Value-added chemicals from food supply chain wastes: State-of-the-art review and future prospects. Chemical Engineering Journal. https://doi.org/10.1016/j.cej.2019.121983

Xu, A., Chang, H., Xu, Y., Li, R., Li, X., \& Zhao, Y. (2021). Applying artificial neural networks (ANNs) to solve solid waste-related issues: A critical review. Waste Management, 124, 385-402. https://doi.org/ 10.1016/j.cej.2019.121983

Xu, J., Zhu, M., \& Zhao, S. (2020). Leader-follower optimized approach for carbon-economy equilibrium in the municipal solid waste (MSW) incineration industry. Environmental Science and Pollution Research International, 27(26), 32637-32658. https://doi.org/10.1007/s11356-020-09076-6 
Xu, L., Ling, M., Lu, Y., \& Shen, M. (2017). External influences on forming residents' waste separation behaviour: Evidence from households in Hangzhou, China. Habitat International, 63, 21-33. https:// doi.org/10.1016/j.habitatint.2017.03.009

Xu, S., Kong, X., Liu, J., Zhao, K., Zhao, G., \& Bahdolla, A. (2016). Effects of high-pressure extruding pretreatment on MSW upgrading and hydrolysis enhancement. Waste Management, 58, 81-89. https:// doi.org/10.1016/j.wasman.2016.07.012

Yadav, V., Kalbar, P. P., Karmakar, S., \& Dikshit, A. (2020). A two-stage multi-attribute decision-making model for selecting appropriate locations of waste transfer stations in urban centers. Waste Management, 114, 80-88. https://doi.org/10.1016/j.wasman.2020.05.024

Yadav, V., \& Karmakar, S. (2020). Sustainable collection and transportation of municipal solid waste in urban centers. Sustainable Cities and Society, 53, 101937. https://doi.org/10.1016/j.scs.2019.101937

Yan, M., Zhang, S., Wibowo, H., Grisdanurak, N., Cai, Y., Zhou, X., \& Kanchanatip, E. (2020). Biochar and pyrolytic gas properties from pyrolysis of simulated municipal solid waste (SMSW) under pyrolytic gas atmosphere. Waste Disposal \& Sustainable Energy, 2, 37-46. https://doi.org/10.1007/ s42768-019-00030-y

Yousefloo, A., \& Babazadeh, R. (2020). Mathematical Model for Optimizing Green Waste Recycling Networks Considering Outsourcing. Industrial \& Engineering Chemistry Research, 59(17), 8259-8280. https://doi.org/10.1021/acs.iecr.9b06876

Yu, X., Sui, Q., Lyu, S., Zhao, W., Liu, J., Cai, Z., Yu, G., \& Barcelo, D. (2020). Municipal Solid Waste Landfills: An Underestimated Source of Pharmaceutical and Personal Care Products in the Water Environment. Environmental Science \& Technology, 54(16), 9757-9768. https://doi.org/10.1021/acs. est.0c00565

Yue, L., Cheng, J., Hua, J., Dong, H., Zhou, J., \& Li, Y.-Y. (2020). Improving fermentative methane production of glycerol trioleate and food waste pretreated with ozone through two-stage dark hydrogen fermentation and anaerobic digestion. Energy Conversion and Management, 203, 112225. https://doi. org/10.1016/j.enconman.2019.112225

Zaeimi, M. B., \& Rassafi, A. A. (2021). Optimization Model for Integrated Municipal Solid Waste System Using Stochastic Chance-Constraint Programming under Uncertainty: A Case Study in Qazvin Iran. Journal of Advanced Transportation. https://doi.org/10.1155/2021/9994853

Zambrano-Monserrate, M. A., Ruano, M. A., \& Ormeño-Candelario, V. (2021). Determinants of municipal solid waste: A global analysis by countries' income level. Environmental Science \& Pollution Research. https://doi.org/10.1007/s11356-021-15167-9

Zhang, B., Lai, K.-H., Wang, B., \& Wang, Z. (2019). From intention to action: How do personal attitudes, facilities accessibility, and government stimulus matter for household waste sorting? Journal of Environmental Management, 233, 447-458. https://doi.org/10.1016/j.jenvman.2018.12.059

Zhang, H., Liu, J., Wen, Z.-G., \& Chen, Y.-X. (2017). College students' municipal solid waste source separation behavior and its influential factors: A case study in Beijing, China. Journal of Cleaner Production, 164, 444-454. https://doi.org/10.1016/j.jclepro.2017.06.224

Zhang, H., \& Wen, Z.-G. (2014). Residents' household solid waste (HSW) source separation activity: A case study of Suzhou China. Sustainability, 6(9), 6446-6466. https://doi.org/10.3390/su6096446

Zhang, H., Wen, Z., \& Chen, Y. (2016). Environment and economic feasibility of municipal solid waste central sorting strategy: A case study in Beijing. Frontiers of Environmental Science Engineering, 10(4), 10. https://doi.org/10.1007/s11783-016-0852-Z

Zhang, J., Hu, Q., Qu, Y., Dai, Y., He, Y., Wang, C.-H., \& Tong, Y. W. (2020a). Integrating food waste sorting system with anaerobic digestion and gasification for hydrogen and methane co-production. Applied Energy, 257, 113988. https://doi.org/10.1016/j.apenergy.2019.113988

Zhang, Y., Banks, C. J., \& Heaven, S. (2012). Anaerobic digestion of two biodegradable municipal waste streams. Journal of Environmental Management, 104, 166-174. https://doi.org/10.1016/j.jenvman. 2012.03.043

Zhang, Y., Cui, Y., Liu, S., Fan, L., Zhou, N., Peng, P., Wang, Y., Guo, F., Min, M., \& Cheng, Y. (2020b). Fast microwave-assisted pyrolysis of wastes for biofuels production-A review. Bioresource Technology, 297, 122480. https://doi.org/10.1016/j.biortech.2019.122480

Zhao, L., Zou, J., \& Zhang, Z. (2020). Does China's Municipal Solid Waste Source Separation Program Work? Evidence from the Spatial-Two-Stage-Least Squares Models. Sustainability, 12(4), 1664. https://doi.org/10.3390/su12041664

Zheng, P., Zhang, K., Zhang, S., Wang, R., \& Wang, H. (2017). The door-to-door recycling scheme of household solid wastes in urban areas: A case study from Nagoya, Japan. Journal of Cleaner Production, 163, S366-S373. https://doi.org/10.1016/j.jclepro.2016.03.106 
Zhi, Z., Pan, Y., Lu, X., Zhen, G., Zhao, Y., Zhu, X., Xiong, J., \& Zhao, T. (2019). Electrically regulating co-fermentation of sewage sludge and food waste towards promoting biomethane production and mass reduction. Bioresource Technology, 279, 218-227. https://doi.org/10.1016/j.biortech.2019.01. 142

Zhou, C., Jiang, D., \& Zhao, Z. (2017). Quantification of greenhouse gas emissions from the predisposal stage of municipal solid waste management. Environmental Science \& Technology, 51(1), 320-327. https://doi.org/10.1021/acs.est.6b05180

Zhou, H., Meng, A., Long, Y., Li, Q., \& Zhang, Y. (2014). An overview of characteristics of municipal solid waste fuel in China: Physical, chemical composition and heating value. Renewable and Sustainable Energy Reviews, 36, 107-122. https://doi.org/10.1016/j.rser.2014.04.024

Zhu, Y., Zhang, Y., Luo, D., Chong, Z., Li, E., \& Kong, X. (2020). A review of municipal solid waste in China: Characteristics, compositions, influential factors and treatment technologies. Environment, Development and Sustainability. https://doi.org/10.1007/s10668-020-00959-9

Publisher's Note Springer Nature remains neutral with regard to jurisdictional claims in published maps and institutional affiliations. 